\title{
Station Service Power Supply for a Hanford Nuclear Energy Center (HNEC)
}

R. L. Richardson

W. J. Dowis

December 1976

Prepared for the Energy Research and Development Administration under Contract E(45-1)-1830 


\section{NOTICE}

This report was prepared as an account of work sponsored by the United States Government. Neither the United States nor the Energy Research and Development Administration, nor any of their employees, nor any of their contractors, subcontractors, or their employees, makes any warranty, express or implied, or assumes any legal liability or responsibility for the accuracy, completeness or usefulness of any information, apparatus, product or process disciosed, or represents that its usẹ wouid not infringe privately owned rights.

PACIFIC NORTHWEST LABORATORY

operated by

BATTELLE

for the

ENERCY RESEARCH AND DEVELOPMENT ADMINISTRATION

Under Contract EY-76-C-06-1830

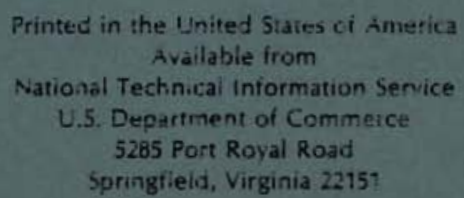

Price: Printed Copy 5

$\therefore$ Microfiche 53.00

$\begin{array}{cc}\text {-Pages } & \text { NTIS } \\ \text { Setling Price } \\ 001-025 & 54.50 \\ 025-050 & 55.00 \\ 05 i-075 & 55.50 \\ 076-100 & 56.00 \\ 101-125 & 56.50 \\ 126-150 & 57.00 \\ -51-175 & 57.75 \\ 176-200 & 58.50 \\ 201-225 & 53.75 \\ 226-250 & 59.00 \\ 25 i-275 & 570.00 \\ 276-200 & 570.25\end{array}$


BNWL -2076

UC- 80

33679000624751

STATION SERVICE POWER SUPPLY FOR A HANFORD NUCLEAR ENERGY CENTER (HNEC)

R. L. Richardson

W. J. Dowis, Consultant

December 1976

Battelle Pacific Northwest Laboratories Richland, Washington 99352 


\section{SUMMARY AND CONCLUSIONS}

The main task of this study was to select an "alternate" station service supply system for multiple plants in the HINEC situation. A nuclear energy center at Hanford (HNEC) in the year 2000 is envisaged as five groups of generating units with three to five units in each group, served by three main $500 \mathrm{kV}$ switching stations. The bulk power system for the Northwest Power Pool is at $500 \mathrm{kV}$; in addition, a $230 \mathrm{kV}$ system that traverses the area will be interconnected with the $500 \mathrm{kV}$ system at Vantage and Grand Coulee to the north and at McNary to the south of the Hanford Reservation. The power source for the station service circuits can be either the 500 or $230 \mathrm{kV}$ systems or the $24 \mathrm{kV}$ generator bus to the stepup transformer to the $500 \mathrm{kV}$ system as shown in Figure 1. The latter alternative, with a switch to isolate the generator, has both functional and economic merit, and was adopted in this study for the "normal" power source in all cases examined. It is equally attractive for dispersed plants or centralized plants.

The assumed grouping of plants is such that the problems of selecting an "alternate" offsite station service supply are similar to those of three and four-unit stations now being designed, nine of which were reviewed for this study. The novel problem at a center of 20 stations is to estimate coincidental peak loads on a system supplying all alternate station service circuits in common under normal and abnormal conditions. NRC's restraints on the operation of a generating station when either of its normal or alternate station service circuits is not available, and the low historical failure rates of equipment in the normal supply circuits act to minimize transferring the load to an alternate circuit. The study indicated that with a possible connected station load of 1200 to $1500 \mathrm{MW}$, the probability of the maximum load exceeding 360 MW would be negligible. An analysis of loads under abnorma1 as well as normal conditions found the peak to be less than $360 \mathrm{MW}$. Load 
EXAMPLE OF $500 \mathrm{kV}-230 \mathrm{kV}$

SYSTEM INTERCONNECTION

THROUGH AUTOTRANSFORMER

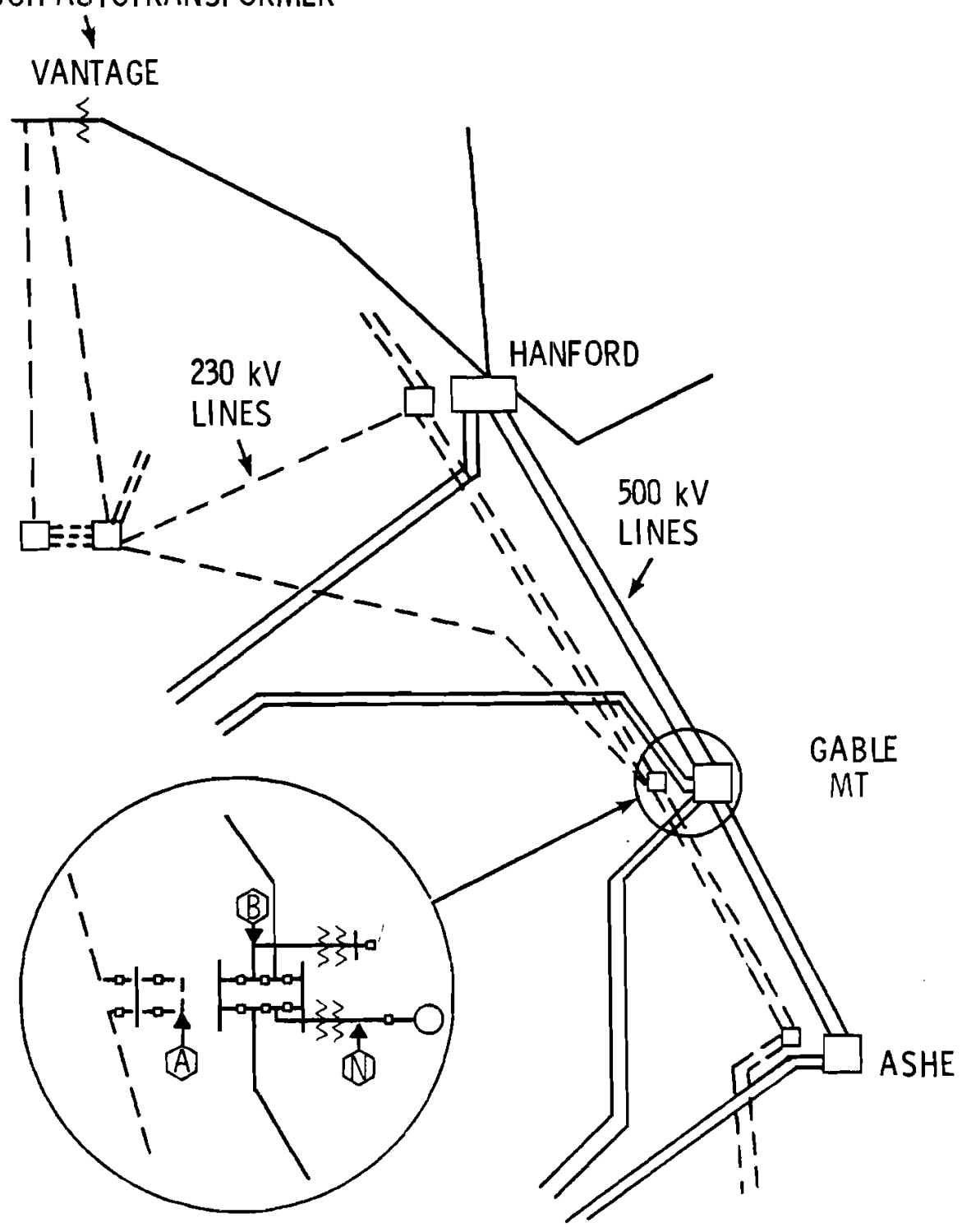

PARTIAL DIAGRAM SHOWING POSSIBLE CONNECTION POINTS BETWEEN GRID

AND STATION SERVICE CIRCUITS:

(1) NORMAL CIRCUIT

(A) ALTERNATE CIRCUIT - CONCEPT A

(B) ALTERNATE CIRCUIT - CONCEPT B

FIGURE 1. HNEC Transmission Systems and Typical Points of

Power Supply for "Offsite" Station Service Circuit 
flow and economic data presented in the report are based on this finding. The data apply only if the station service for all plants is taken from the $230 \mathrm{kV}$ system, designated Concept $A$ in our study. In Concept B alternate circuit power is drawn from the $500 \mathrm{kV}$ station bus, and the question of supply system capacity does not arise.

Load flow studies of the local transmission system indicated that $230 \mathrm{kV}$ system reinforcements necessitated by HNEC station loads would comprise 55 to 60 miles of line in sections from Vantage to Hanford, and from Hanford to Gable Mountain switching stations at a cost of about $\$ 8$ million.

In order to demonstrate the engineering solutions to alternative methods of providing station service, certain assumptions were made with respect to the grouping, spacing, and orientation of the generating plant units, as well as their positions relative to the existing and anticipated main transmission 1 ine routes. In the southern part of the reservation, where development is already taking place, the pattern already established was followed to a total of five generating units. In the central and northern groupings, it was assumed that two-, three- and four-unit stations would resemble those of the Catawba, Palo Verde and Alan Barton designs. The relative positions of the $500 \mathrm{kV}$ and $230 \mathrm{kV}$ switching stations involved assumptions which affect not only the number of underground crossings but also other design features necessary to separate the offsite station service circuits. These assumptions of course influence the comparative cost estimates of concept $A$ and Concept $B$. Finally, the study assumed that the regulatory position now held on this topic by NRC would remain substantially as set forth in guides and standards now in effect or proposed.

Once the study had established those assumptions and base conditions with respect to the development of the HNEC and the development of transmission facilities in the vicinity of the Hanford Reservation, we then considered various means of providing alternate circuits to serve the station loads of 20 units. The two most attractive concepts were:

A. Loop circuits from switching stations on the $230 \mathrm{kV}$ system, serving three to five plants each, with $230 / 6.9 \mathrm{kV}$ or $13.8 \mathrm{kV}(6.9 \mathrm{kV}$ is used 
herein as typical of intermediate voltage) transformation at the station buses of each generating unit.

B. Radial circuits from a 500/69 kV transformer, fed from a 1-1/2 breaker position on the same $500 \mathrm{kV}$ bus carrying the main generator output, and having circuits to $69 / 6.9 \mathrm{kV}$ transformers at each generating station unit (69 kV allows for extensive distance between switchyard and load).

The technical and operational merits of Concepts $A$ and $B$ were compared. No major differences were found with respect to the potential effects of the circuit characteristics on generating plant availability or on continuity of service to safety related plant loads. Significant differences were found in environmental effects, in the degree of uncertainty regarding regulatory position, and in flexibility for sporadic growth; these differences are discussed in the conclusions.

The estimated capital investment cost for the normal and alternate circuit 1 ines and equipment, and grid reinforcements, for 17 additional generating plants at HNEC is $\$ 78$ million for Concept $A$ and $\$ 79 \mathrm{million}$ for Concept $B$. A greater portion of the investment of Concept $B$ comes early in the HNEC development period; the discounted present worth of the required capital investment is from 10 to $15 \%$ greater than that of Concept $A$.

In addition to the specific combinations of Concepts $A$ and $B$, other possible methods or combinations were considered, some involving three offsite circuits instead of two, and one having a separate generating source to provide an alternate supply for ali plants. A plant design with a bifurcated main generator bus would provide a good opportunity for having both offsite station service supply circuits on the generator bus. This combination appears to be both functionally and economically superior to most other designs; however, this design can only be used when the design of the major power circuits is already a bifurcated system and very few plants have such systems. The other alternatives were not attractive, and any advantage they may have would not warrant the added cost. 
In conclusion, our study indicated that there are acceptable methods of providing station service to a 20-unit HNEC. The choice of method would depend on the economic, environmental and technical situation at the time the design of a new plant is committed, and on the preference of the responsible utility. Briefly, our study yielded the following conclusions:

- Extraordinary engineering difficulties in designing an HNEC's station service systems that will meet all utility and regulatory requirements are not anticipated.

- The choice of the $230 \mathrm{kV}$ system (Concept A) involves the uncertainty of whether the NRC would require full capacity in the BPA system for all possible connected load. The capacity estimates herein are based on expectation of peak loads of only $24-30 \%$ of possible connected load; this expectation is based on a study of the probabilities of the number of operating plants simultaneously transferred to the alternate system.

- Either of the two alternate circuit concepts, Concept A or B, studied in detail would be acceptable based on safety and operability.

- The estimated costs of the two alternatives are roughly equal for the set of conditions assumed in this study, but Concept $A$ has a 10 to $15 \%$ advantage in discounted present worth of required investment. Different geographical arrangements of plants and switching stations would affect the estimates, but not to the extent that one concept would have a marked economic advantage over the other.

- The principal advantage of Concept $A$, in which station service (alternate circuit) is taken from the $230 \mathrm{kV}$ system, is that the method is flexible enough to accommodate sporadic growth of the number of generating stations planned at Hanford--that is, in the absence of a firm program for completion of a three- or four-unit group or for a ful1scale HINEC development. This concept is already in use for plants planned in the vicinity of the Ashe switching station. 
- The principal advantages of Concept $B$, in which the station service (alternate circuit) is taken from the $500 \mathrm{kV}$ system, are: (1) it does not require any added offsite transmission line construction, thus involving no added environmental impact; and (2) the inherent capacity in the network is ample for any load combination, thus avoiding any uncertainty as to the regulatory agencies' position on required capacity in network transmission lines.

- Other station service supply methods or combinations which would meet operational and safety requirements are possible but at higher cost and without substantial added benefits. 


\section{CONTENTS}

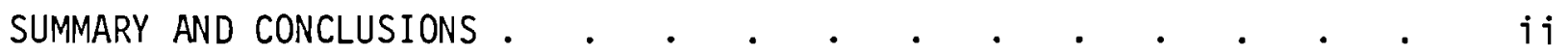

LIST OF FIGURES .

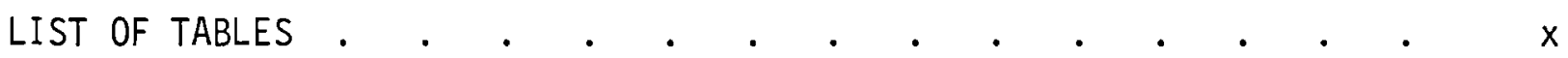

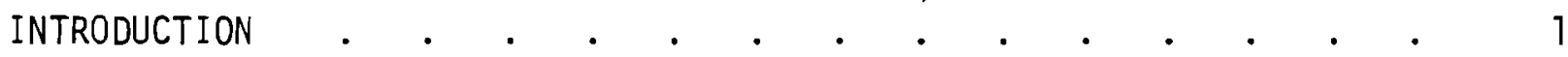

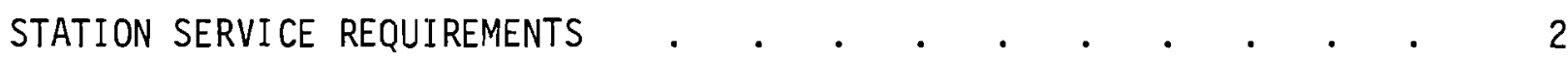

STATION DEMAND .

SAFETY REQUIREMENTS OF STATION SERVICE SUPPLY SYSTEM . . . . 3

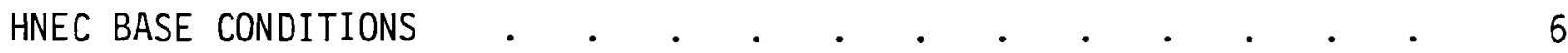

ALTERNATE CONCEPTS FOR A 20-UNIT CENTER . . . . . . . . . 10

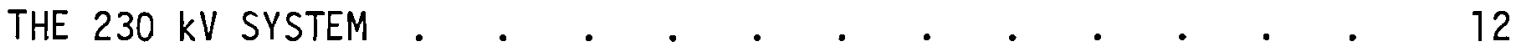

Station Service Loads Under Abnormal Conditions . . . 15

230 kV System Description. . . . . . . . . 17

Additions for $230 \mathrm{kV}$ Supply . . . . . . . . . 18

Operation . . . . . . . . . . . . . . . 19

Analys is of the Projected 1990 System . . . . . . 19

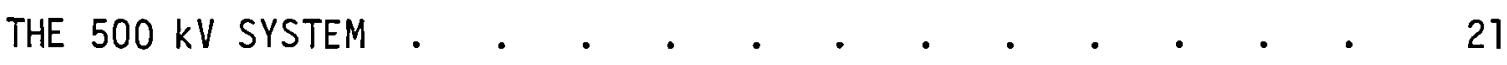

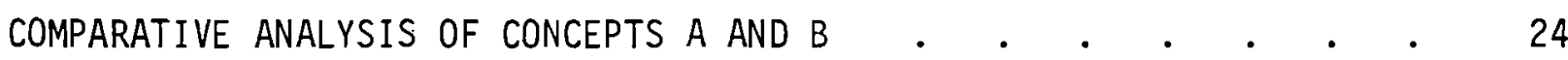

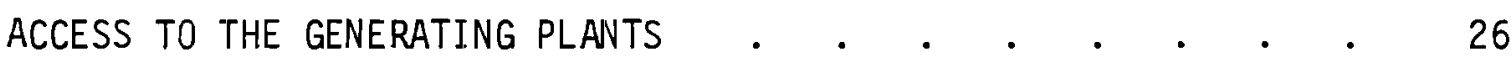

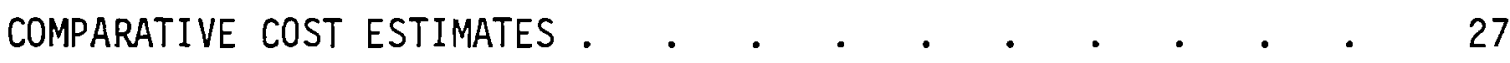

Capital Investment at the Site . . . . . . . 27

Costs of BPA System Reinforcement . . . . . . . 27

Timing of the Investment Requirements . . . . . . 30

Operating Cost . . . . . . . . . . . . . 31

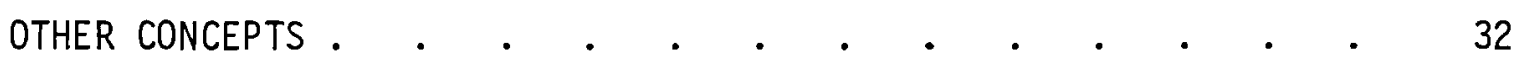

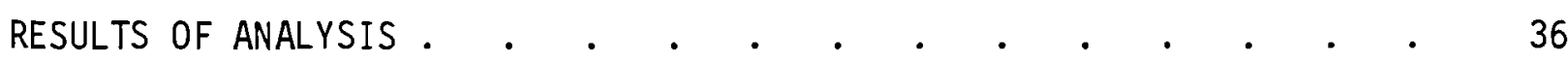

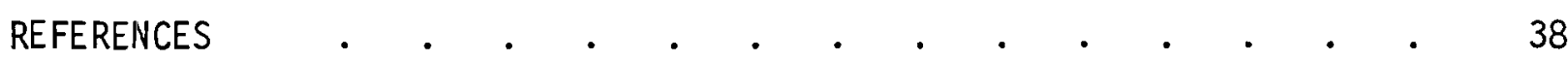

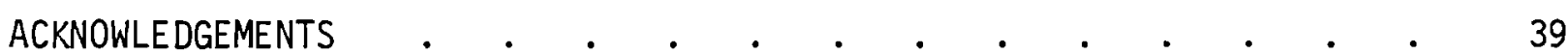

APPENDIX A - LIST OF ACCEPTANCE CRITERIA FOR ELECTRIC POWER . . . A-1

APPENDIX B - SCHEMATIC ARRANGEMENTS FOR OFFSITE STATION

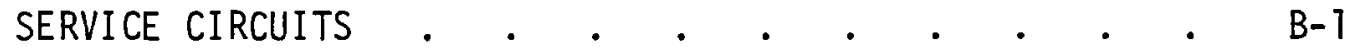

APPENDIX C - LOAD-FLOW DIAGRAMS . . . . . . . . . . .

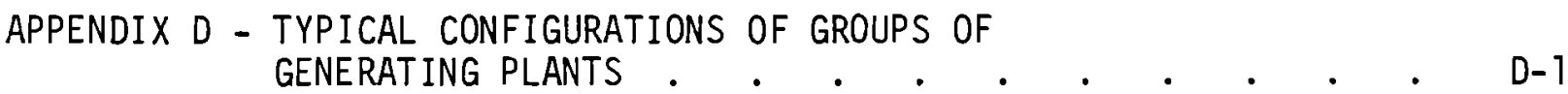




\section{LIST OF FIGURES}

1. HNEC Transmission Systems and Typical Points of

Power Supply for "Offsite" Station Service Circuit . . . . . . ii

2. Range of Typical Station Service Loads for a

1200 MW Generating Plant . . . . . . . . . . . . 3

3. HNEC Tentative Sites . . . . . . . . . . . . . . . 7

4. Genera 1 Route of 1985 Hanford $230 \mathrm{kV}$ System . . . . . . . . 9

5. Schematic Diagram of Station Service Circuits, Concept A . . . . 10

6. Schematic Diagram of Station Service Circuits, Concept B . . . . 11

7. HNEC Switching Stations for (230 kV System) 20 Generating Units . . 18

8. Hanford Area $230 \mathrm{kV}$ System with $360 \mathrm{MW}$ Load at Ashe . . . . . 20

9. Switching Stations HNEC-24,000 MW $(500 \mathrm{kV})$. . . . . . . . . 22

10. Estimated Cumulative Investment in Alternate Circuit
Station Service Lines and Equipment . . . . . . . . . 30

B.1 Hanford No. 2 . . . . . . . . . . . . . . . . . . B-4

B.2 Hanford No. 1 and 4 . . . . . . . . . . . . . . . . B-4

B.3 Hartzville - 4 Units . . . . . . . . . . . . . . . . B-5

B.4 Alvin Vogtle - 4 Units . . . . . . . . . . . . . . B-5

B.5 North Anna - 4 Units . . . . . . . . . . . . . . . . B-6

B.6 Palo Verde -3 Units . . . . . . . . . . . . . . . . B-6

B.7 Alan Barton . . . . . . . . . . . . . . . . . . . B-7

B.8 Shearon Harris . . . . . . . . . . . . . . . . . . B-7

B.9 McGuire (a 2-Unit Plant) . . . . . . . . . . . . . . . B-8

C. 1 Hanford Area $230 \mathrm{kV}$ System with 180 MW Load at Hanford, Gable Mt., and Ashe. 115-kV system sectionalized between Midway and Franklin . C-2

C.2 Hanford Area 230 kV System with 180 MW Load at Hanford, Gable Mt., and Ashe. 115-kV system sectionalized. . . . . . . . . . C-2

C.3 Hanford Area $230 \mathrm{kV}$ System with $180 \mathrm{MW}$ Load at Hanford, Gable Mt., and Ashe. McNary-John Day 500 kV Connection . . . . . . . C-3

C.4 Hlanford Area 230 kV System wi th 180 MW Load at Hanford, Gable Mt., and Ashe . . . . . . . . . . . . . . . C-3

C.5 Hanford Area $230 \mathrm{kV}$ System with $360 \mathrm{MW}$ Load at Gable Mt. . . . C-4

C. 6 Hanford Area $230 \mathrm{kV}$ System with $360 \mathrm{MW}$ Load at Hanford. Scootenay reinforced, 115-kV system sectionalized. 
D.1 Map of Facilities in Vicinity of Ashe Switching Station . . . . D-2

D.2 Map of Facilities in Vicinity of Gable Mountain Switching Station... . . . . . . . . . . . . . . . . D-3

D.3 Map of Facilities in Vicinity of Hanford Switching Station . . . D-4

D.4 Orientation of Principal Structures Planned for Hanford Plants . D-5

D.5 Orientation of Principal Structures for Alan Barton Design . . . D-6

D.6 Orientation of Principal Structures for the Palo Verde Plant . . D-7

\section{$\underline{\text { LIST OF TABLES }}$}

1. Comparison of Technical and Functional Characteristics of Concept A and Concept B . . . . . . . . . . . . . 24

2. Plants Beginning Commercial Operation . . . . . . . . . . 28

3. Investment in Station Service Facilities . . . . . . . . . 28

4. Discounted Present Worth of Alternate Circuit Investments . . . 31

A-1 Acceptance Criteria for Electric Power . . . . . . . . . . A-2

B-1 Number of Generating Units Sharing Station Service Circuits and Equipment . . . . . . . . . . . . . . B-8 
STATION SERVICE POWER SUPPLY FOR A HANFORD NUCLEAR ENERGY CENTER (HNEC)

\section{INTRODUCTION}

A transmission system to provide station service to plants at an energy center is the subject of this report, which follows from a study of transmission of electric power from an energy center at Hanford conducted by Battelle Pacific Northwest Laboratories with the assistance of the Bonneville Power Administration and reported in BNWL-B-426 Electric Power Transmission for a Nuclear Energy Center, (1) September 1975. Both studies were conducted for the Energy Research and Development Administration (ERDA).

The study's main task was to evaluate and select an "alternate" station service supply system for multiple plants in an HNEC situation. Designs have been developed in the U.S. for station service power supply systems for fourunit plants. Some of these designs have already been approved by NRC as complying with safety regulations, and have been accepted by utilities as providing for an adequate level of operating reliability and flexibility. Plans for three units have been approved at Hanford, and a system has been developed for a total of five units in one general locality. The study reported herein concerns the requirements for station service to a nuclear energy center of 20 units with a net capacity of 24 gigawatts $(24,000 \mathrm{MW})$.

The specific case studied is that of station service supply for the $150 \%$ Case (i.e., a transmission system to accommodate growth of generating capacity to 23,000 MW by 1998) in the reference transmission study. (1) The anticipated rate of load growth is such that an energy center could have a total generating capacity of $24 \mathrm{GW}$ by the year 2000. The scope of the study includes the station service transmission system from its offsite origin in the bulk power network to the station service buses in the plant. The internal redundant systems extending from those buses to the station loads would not be expected to differ because of the number of generating units in one complex. 


\section{STATION SERVICE REQUIREMENTS}

The discussion of station service requirements relies on the following terms and definitions:

- Offsite Power System: The offsite external commercial power system from which station service power can be supplied.

- Standby Power System: The onsite power sources, usually diesel generators, and their distribution equipment provided to energize devices essential to safety and capable of operating independently of the offsite power system. (2)

- Normal offsite Circuit: The circuit or circuits from the offsite power system that are normally used.

- Alternate Offsite Circuit: The circuit or circuits from the offsite power system that are used only when the normal circuit or circuits are out of service.

A station service supply system is designed to not only meet the station loads and the plant safety requirements set by the NRC, but also to comply with the utilities' requirements for satisfactory overall performance of the plant. Specific requirements vary with the character of the network to which the plant is to be connected.

\section{STATION DEMAND}

Station demand for typical light-water reactor plants has been estimated from compilations of connected loads and analysis of the operating sequences of plant equipment in various operating modes. These estimates were then checked with loads experienced in operating plants. The resulting range of station service electrical demands of one 1200-MW nuclear generating unit is shown in Figure 2. Station loads for 1200-MW units are usually less than $75 \mathrm{MW}$. In later discussion of load diversity, $75 \mathrm{MW}$ is taken as a conservative average load of operating reactors, $40 \mathrm{MW}$ as load under hot standby, and $13 \mathrm{MW}$ under cold shutdown. 


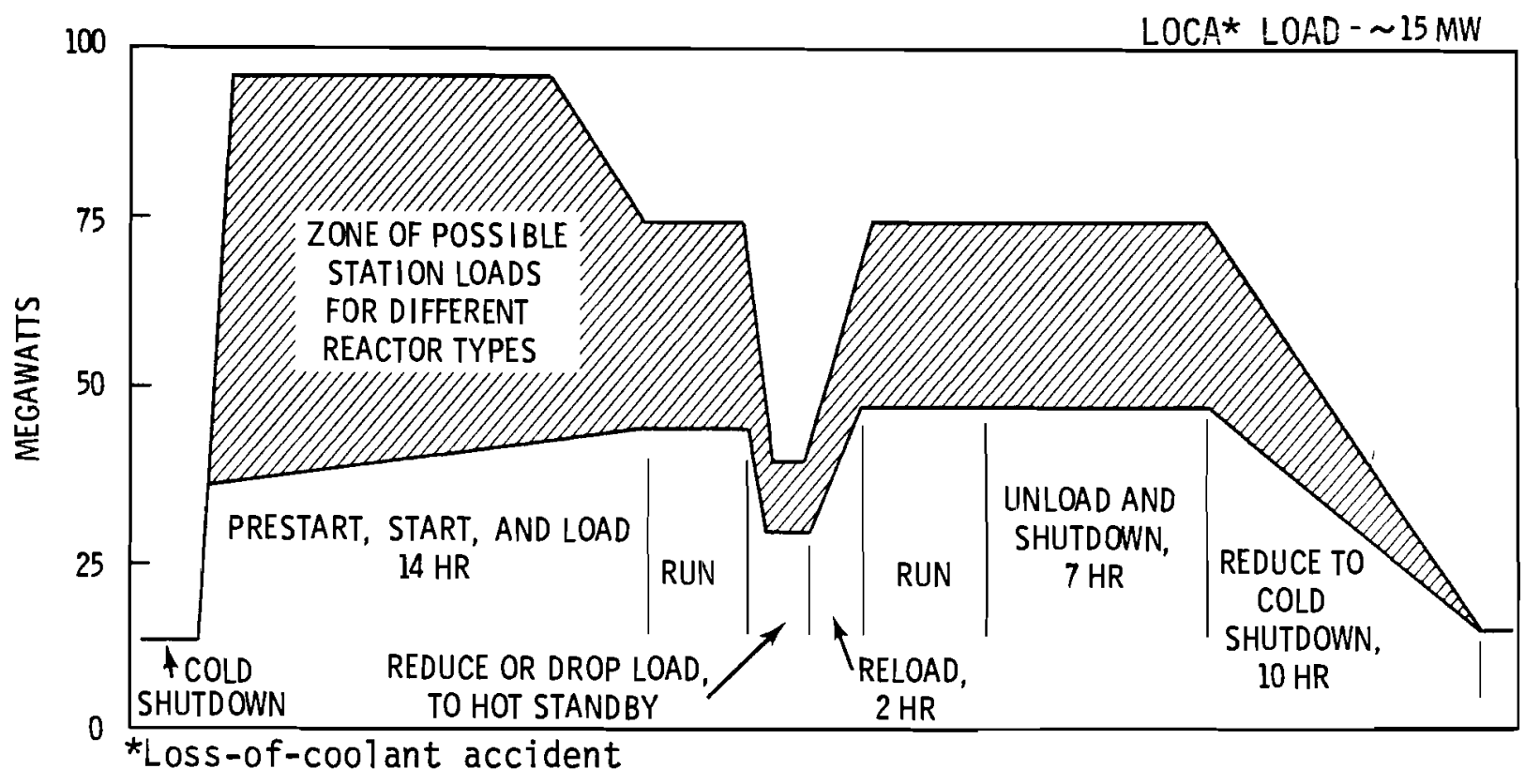

FIGURE 2. Range of Typical Station Service Loads for a 1200 MW Generating Plant

SAFETY REQUIREMENTS OF STATION SERVICE SUPPLY SYSTEM

Safety requirements specifically demand that two independent offsite sources of power be available to each reactor. This offsite power system is normally referred to as the "preferred power system." The preferred power system is acceptable when two separate paths from the transmission network to the standby power distribution system are provided; adequate physical and electrical separation between the two paths exists; and the system has the capacity and reliability to supply power to all equipment essential to the safety of the plant. The two separate paths are designated as the "normal" and "alternate" offsite circuits throughout this report.

It is instructive to realize what equipment will be reviewed for safety in the preferred power system. It includes the two (or more) identified power sources that can be operated independently of the onsite (station generator) 
or standby power sources (diesel generators). It encompasses the grid, transmission lines (overhead or underground), transmission line towers, transformers, switchyard components and control systems, switchyard battery systems, the main generator, and disconnect switches, all provided to supply electric power to safety-related and other equipment. These components and associated systems will be subjected to a safety review. Special integrity checks for components will be made and the systems using these components will be subjected to a single failure analysis which checks that no single failure such as a tower falling, or a line failure, or a single failure in a switchyard can simultaneously affect both circuits such that neither can be returned to service "within a few seconds." (3)

One of the above safety considerations--that of providing adequate physical and electrical separation--may affect the design of preferred power sources and is especially true where many sites are involved. NRC proposes, for instance, that no other line cross these circuits, which would thus force underground crossing in addition to other measures not normally included in providing offsite station service to non-nuclear generating plants.

Insofar as the preferred power system is a part of a station service supply system, the capacity required merely for its operating flexibility would normally be far greater than the demands for safety. That is, overal1 plant demand for normal operation would be expected to exceed the demands of station loads essential to safety. However, the whole preferred power system will be examined specifically for all of the safety criteria. Those safety criteria for offsite electrical power are set by NRC and IEEE and are listed in Appendix A.

In spite of their number, the guides, standards and criteria provide only general guidance. The Nuclear Regulatory Commission bases its approval on an individual case review. Several examples of designs for preferred power sources, in Appendix B, illustrate the variety of schematic design that has been proposed. These designs of preferred power sources completed for multiple station power units have been ruled acceptable for existing projects. 
Such criteria as physical and electrical independence, capacity to satisfy several conditions, the grid stability of the preferred (offsite) power source, the demand that the system function under single failure criteria-all may require design features not normally considered for operating flexibility and operating stability. However, none of these criteria appear to be limiting in any way to the concept of multiple station sites.

Thus, in answer to questions regarding the comparative safety of distributed or concentrated concepts of power generation, concentration of generation at a center would create no unresolvable safety problems relative to offsite power. Further, the existence of the large number of units at an energy center will no doubt result in greater usable backup capability and increased reliability of the preferred power sources. 


\section{HNEC BASE CONDITIONS}

Tentative sites selected for nuclear plants are shown in circles on the map of Figure 3, and general areas suitable for the construction of, or expansion of, transmission switching stations are shown as squares. Corridors considered suitable for transmission lines are also shown.

Three WPPSS nuclear plants are in various stages of design and construction in area No. 1, with some switching station equipment now installed at the Hanford Station and some planned for the Ashe Station. A transmission line right-of-way is being established between the Hanford and Ashe Stations. The bulk power transmission plant to accommodate up to 24,000 MW at HNEC would be expanded from that already in place or planned.

This report assumes that circled areas 1 through 5 wi11 be developed, with three to five generating units per area. The manner in which station service transmission lines are brought into the generating plants would depend on plant layout. To illustrate the possible methods of providing for station service, it is assumed that

(1) The plants in or around area No. 1 would develop consistent with the pattern already established by the three plants now planned, with a considerable distance separating each unit.

(2) The plants in areas No. 2 through 5 would be two-, three-, or fourunit aggregations similar to those planned for the Catawba, Palo Verde or Alan Barton plants, respectively. However, the switching stations for the Hanford plants would not be as close (around 1500 feet) to the station transformer bays as are the Catawba, Palo Verde and Alan Barton plants, but would be greater distances as determined by the location of the Ashe and Hanford switching stations and the proposed location of the Gable Mountain station shown in Figure 3.

These assumptions potentially affect the choice of station service method in that: 


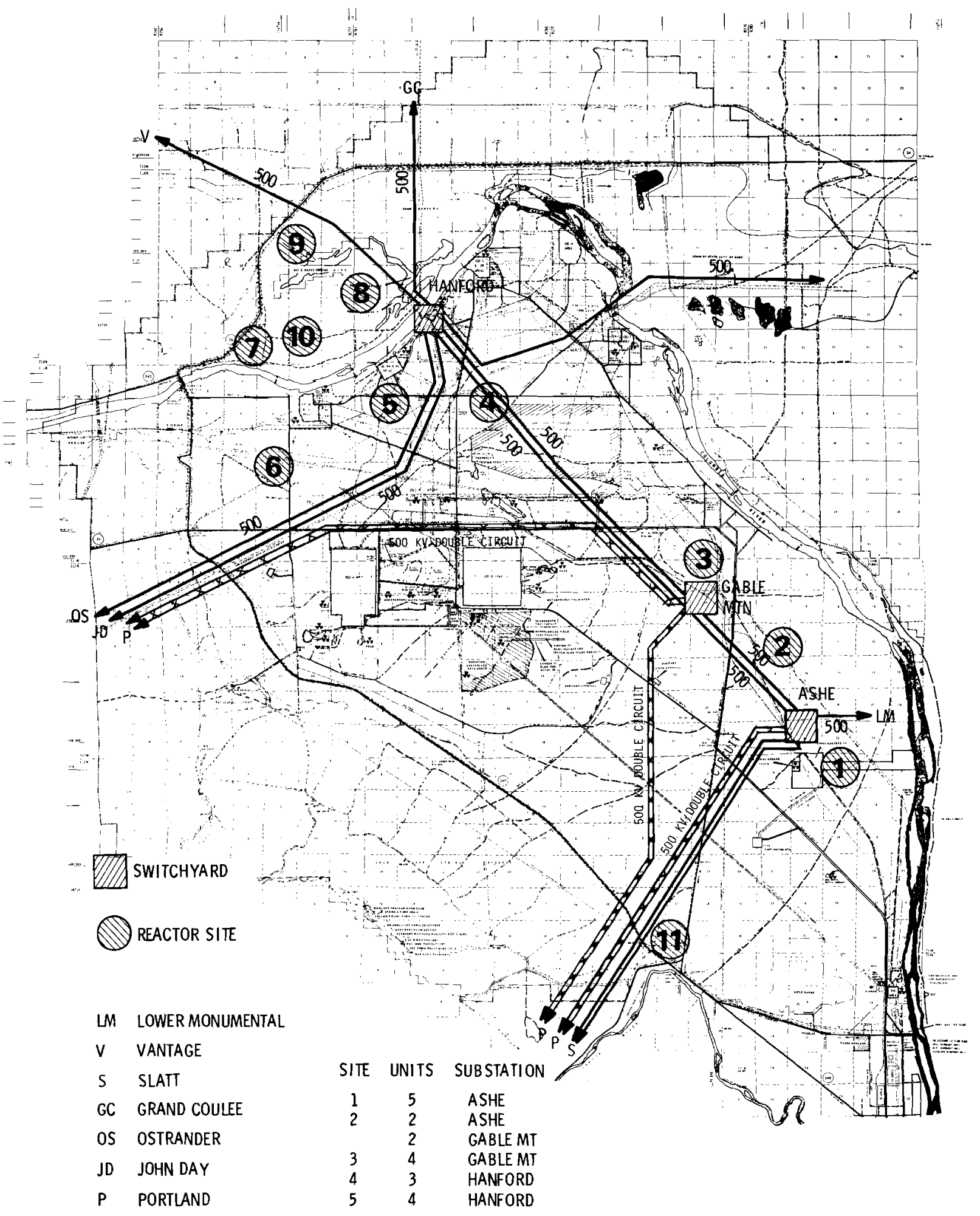

FIGURE 3. HNEC Tentative Sites 
(1) If one of the offsite circuits originates at the $500 \mathrm{kV}$ switching station bus, a greater distance between the bus and the generating plant must be traversed by the station service ciruit than with a closer orientation,

(2) If an effort is made to keep a $230 \mathrm{kV}$ switching station in the same general area as the $500 \mathrm{kV}$ switching stations, more crossover situations may be encountered, and

(3) With closely spaced units, more underground cable may have to be used in station service circuits between units than if the units are spaced at greater distances.

The feasibility of the $230 \mathrm{kV}$ system as an offsite source will depend on the location of $230 \mathrm{kV}$ lines in place in 1985. BPA already plans to extend them or increase their capacity for reasons other than the HNEC station service load. The general route of the $230 \mathrm{kV}$ system to be in place in 1985 is shown in Figure 4 relative to the possible location of generating plants. Note that $230 \mathrm{kV}$ lines pass close to all of the sites 1 through 5; thus that system is a definite candidate for HNEC station service. The way in which the system would have to be strengthened to serve that purpose is discussed later (see "Additions for 230 kV Supply"). 


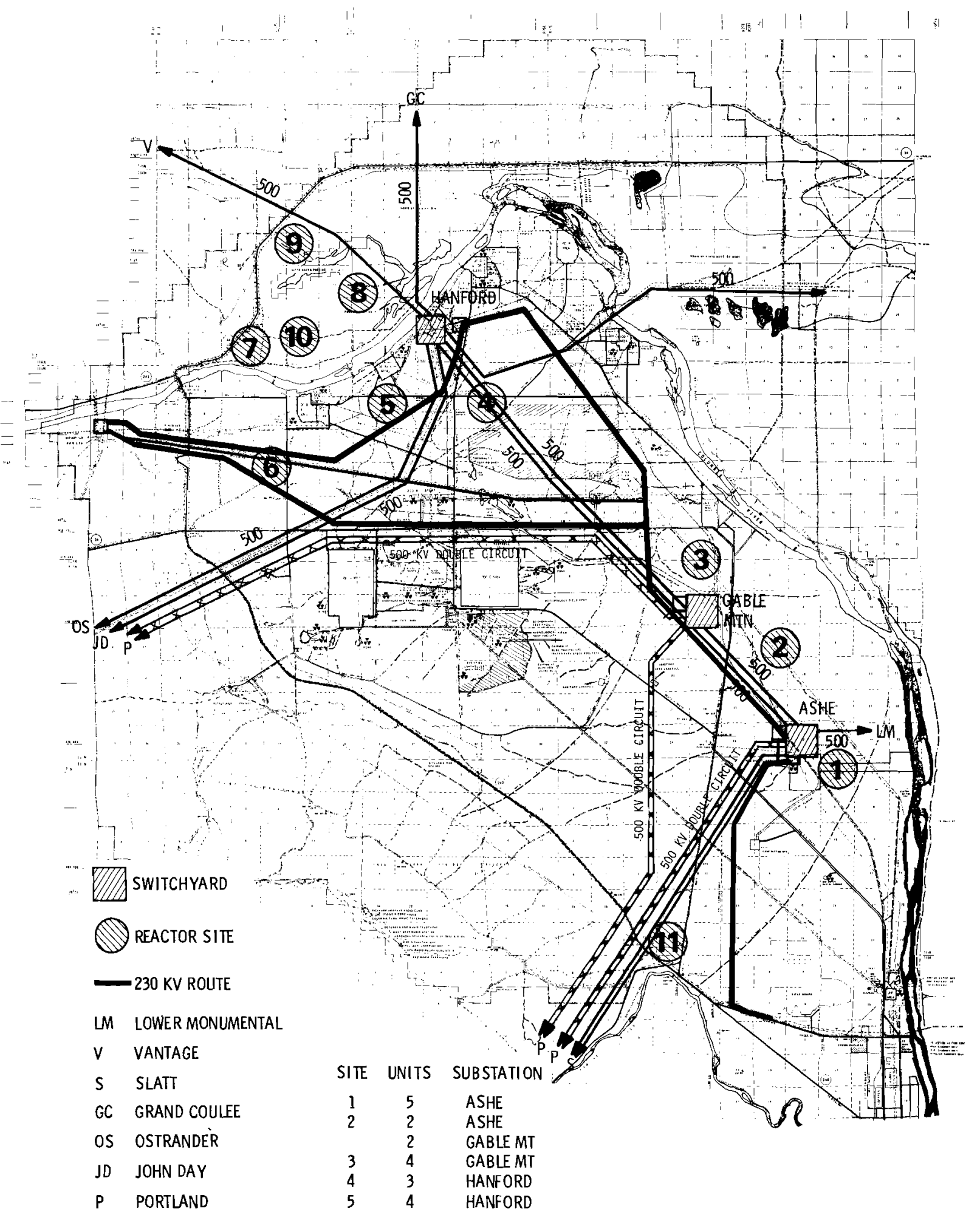

FIGURE 4. General Route of 1985 Hanford $230 \mathrm{kV}$ System 


\section{ALTERNATE CONCEPTS FOR A 20-UNIT CENTER}

Station service designs for existing or planned three- and four-unit plants are outlined in Appendix B. The major scenarios considered for HNEC are:

(1) A concept in which the normal circuit originates at the generator terminal bus but is capable of being disconnected from the generator by a load-break circuit breaker, and in which the alternate circuit originates in the $230 \mathrm{kV}$ portion of the network. The concept follows the general pattern established for two of the three planned commercial plants at Hanford and is shown schematically in Figure 5 as Concept A.

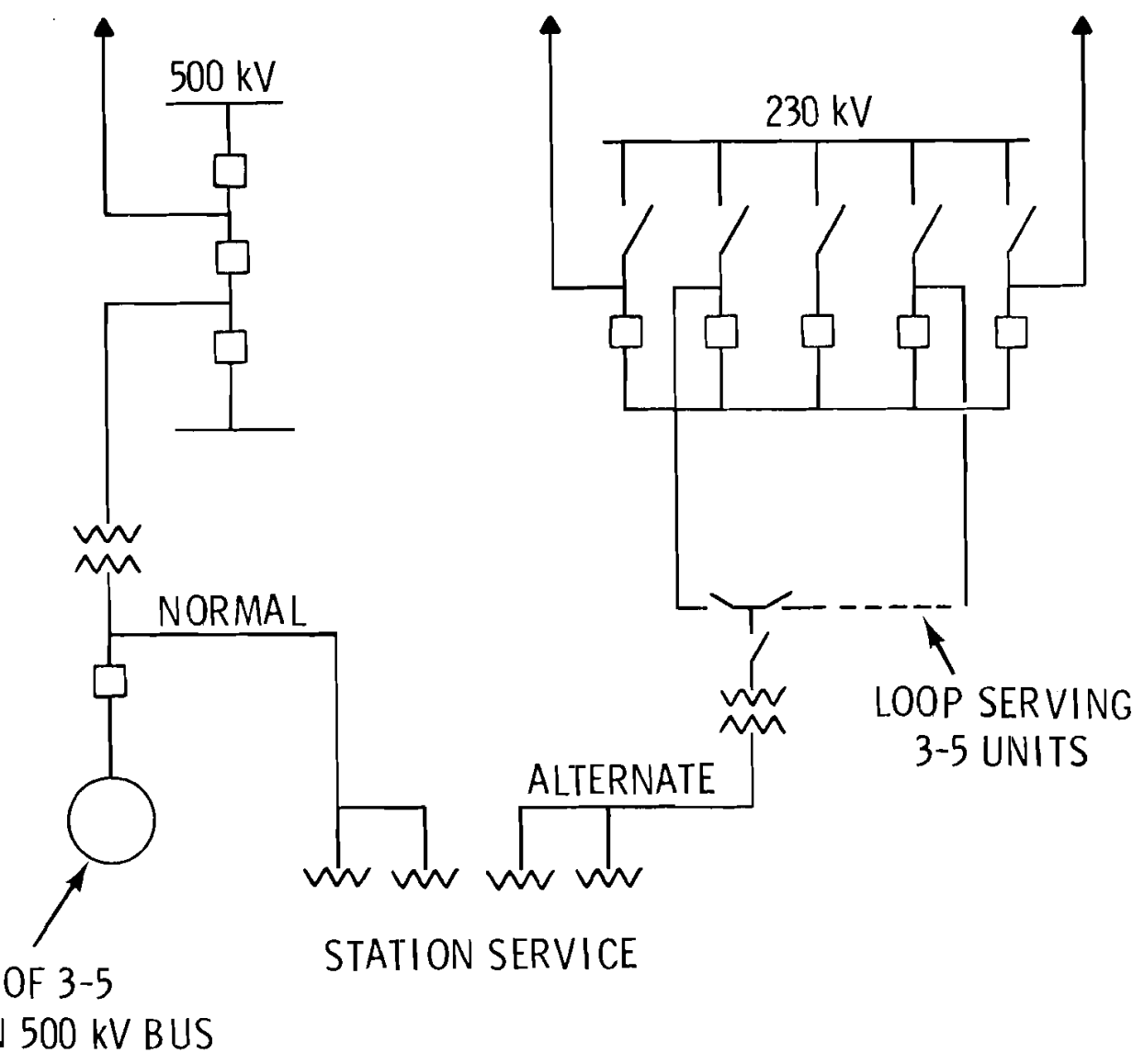

FIGURE 5. Schematic Diagram of Station Service Circuits, Concept A 
(2) A concept in which the normal circuit is as above, but with the alternate circuit originating in the $500 \mathrm{kV}$ switchyard on a breaker-and-a-half position as shown in Figure 6 as Concept $B$. This concept would eliminate the necessity for routing additional $230 \mathrm{kV}$ lines through the HNEC. Such an arrangement is similar to, but not identical to, that used at the Palo Verde, Alan Barton, and Shearon Harris plants.

Other concepts were explored but were found to be less attractive. They are discussed briefly in a later section of the report.

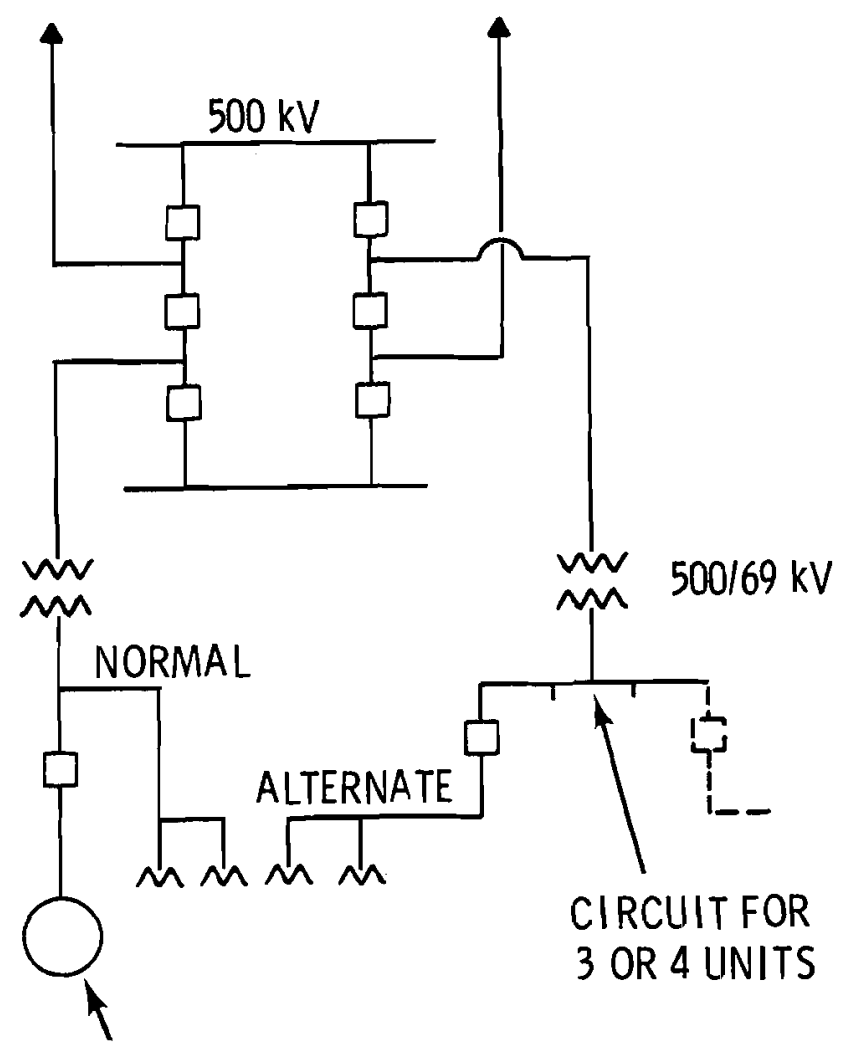

ONE OF 3 OR 4

UNITS ON $500 \mathrm{kV}$ BUS

FIGURE 6. Schematic Diagram of Station

Service Circuits, Concept B 


\section{THE $230 \mathrm{kV}$ SYSTEM}

Utilities differ in their practices regarding normal distribution of station loads on the two offsite circuits. Some divide the loads on the two sources and automatically switch half the loads in the event of an outage on one circuit, while others keep all the load on one circuit and automatically switch all the load in the event of an outage on that circuit. This discussion assumes that the latter practice is followed (consistent with WPPSS plans to date) and that all station loads will be on the "normal" circuit at a11 times, except when it is in trouble or the generator bus to which it is attached is taken out of service for inspection, maintenance, or repair.

Most, if not a11, of the nuclear plants now in operation do not have load-break switches between the generator terminals and the station service tap. If the tap circuit is used normally, the operator has no option but to transfer station loads to the alternate offsite circuit (sometimes called the startup circuit) when the plant is shut down or starting up. Therefore, there is no record of experienced use of the alternate circuit under conditions identical to those of Concepts $A$ and $B$ among operating plants. However, certain station operators report that:

(1) Alternate circuits are used only when the plant is shut down or starting up.

(2) Trouble in a normal circuit with its tie-in point in the network seldom occurs, and with its tie-in point on the generator bus, seldom if ever occurs.

(3) There has been no occasion to exercise an option to manually transfer to the alternate circuit during plant operation.

Such experience indicates that with a load-break switch there would be few occasions to transfer station loads to the alternate circuit; such occasions would probably be limited to: (1) switching over in order to inspect or maintain equipment in the bus tap zone, and (2) testing of the 
transfer switchgear and circuits. These operations would normally be expected to occur when the generator was shut down, at which time the station loads transferred would be only about $13 \mathrm{MW}$ per generating unit.

In plants of only one to four units both the normal and the alternate offsite circuits have usually been designed to accommodate the sum of the maximum demands from connected loads on all generating units; however, where 20 units conceivably could be served from a single alternate source, lesser capacity based on load diversity must be considered.

According to NRC safety regulations, the conditions under which the alternate circuit may be used are:

(1) With the generator operating at full or reduced load or at hot standby, but still connected to the system:

(a) When the normal circuit is out of service, the alternate circuit could be used for up to 72 hours on only one source of offsite power. The load would be that corresponding to normal plant operation, possibly followed by the sequence for shutdown.

(b) When the normal circuit is available but an operating option has chosen to use the alternate circuit, the latter could be used indefinitely at a load corresponding to normal plant operation.

(2) With the generator in cold shutdown, at which time operating options could place station loads on the alternate circuit indefinitely.

Under the regulations that limit the use of the alternate circuit to those conditions, the probability of the operating loads of multiple plants being transferred to the alternate circuit is less than if the plant operators were free to use either source on a continuing basis regardless of the state of the other. We estimated that over the average year an operating plant would be on the alternate source because of (1) failure of the normal 
supply or (2) suspected weakness in the normal supply causing the operator to switch over manually, not more than a total of 7 days. A crude way of reducing this experience to probabilities is to say that for $7 / 365$ of the year, exactly one of the 20 plants is operating on the alternate supply while 19 of the 20 plants are operating on the normal supply. This condition evaluates the corresponding term of the binomial series for the probability of that event: ${ }^{(4)}$

$$
20 P^{19}(1-P)=7 / 365 \simeq 0.02 \text {. }
$$

Solving for $p^{20}$ yields $p^{20}=0.979805$. Six figure accuracy was chosen to demonstrate that 0.000001 is the same as an outage of about 32 seconds per year. Here, six figure accuracy assumes that loadings of less than 0.000001 are negligible. Using this data as a basis for further evaluation, the term for any three of the 20 plants simultaneously on the alternate circuit and the remaining 17 units operating on the normal circuit is:

$$
(20)(19)(18) P^{17}(1-P)^{3} /(1)(2)(3)=0.000001 \text {. }
$$

Similar computation yields the following probabilities.

$$
\begin{array}{ll}
\text { One unit switched to the alternate circuit } & 0.020000 \\
\text { Two units switched to the alternate circuit } & 0.000194 \\
\text { Three units switched to the alternate circuit } & 0.000001 \\
\text { Four units switched to the alternate circuit } & \text { negligible }
\end{array}
$$

These probabilities demand that operating continuity of the normal system supply circuit, aside from planned outages, be greater than 0.99898 for each unit. This figure ranges from 0.999495 to 0.997372 when the probability for a single unit of the 20 units switched to the alternate supply ranges from 3.65 to 18.25 days per year, thus indicating that the above probabilities of three or four units being simultaneously transferred to the alternate circuit are not sensitive to the basic assumption (probability of 0.02 ) within the 3.65 to 18.25 day range. When time for scheduled maintenance has been considered, the remaining operation should be characterized by high reliability, and unanticipated outages for each normal circuit unit should be negligibly small. 
If four operating units are used as a design basis $(4 \times 75=300 \mathrm{MW})$, and $20 \%$ is added for units in cold shutdown that may be on the alternate circuit, then the design basis for power capacity in a common supply system would be $360 \mathrm{MW}$. Here, we have adopted the maximum power requirement for station loads as discussed in the section on "Station Demand." The adequacy of a $360 \mathrm{MW}$ base is examined in the following paragraphs.

The probabilities shown above are for calculations based on a worstcase condition in which al1 20 units were on line. On the average only about 16 units will be on line, although maintenance and refueling schedules may be such that for limited periods most of the plants in a center would be operating. When the units are shut down, internal loads are sufficiently low that station service loads of all units could be transferred without exceeding $360 \mathrm{MW}$.

The interim requirements for reinforcement of the $230 \mathrm{kV}$ supply system, calculated on the same basis as the fully developed center and including the three units now planned, are:

$\begin{array}{lll}1983 & 2 \text { units } & 150 \mathrm{MW} \\ 1984 & 3 \text { units } & 225 \mathrm{MW} \\ 1996 & 16 \text { units } & 360 \mathrm{MW}\end{array}$

A later section presents means by which the $230 \mathrm{kV}$ system would be reinforced to provide for (1) the growing loads in the area and (2) the superimposed capacity requirement of an HNEC.

Station Service Loads Under Abnormal Conditions

This section presents some of the possible abnormal conditions and the responses to them. The discussion assumes that a 11 new generating units would be capable of continued operation carrying only local auxiliary loads -after full-load rejection.

One could visualize a system instability that would separate all $500 \mathrm{kV}$ incoming lines from one entire switching station and which would either leave the generators running on hot standby feeding their own station loads, or cause hot standby loads to be transferred to the $230 \mathrm{kV}$ system. 
In this situation, since a11 units would be expected to handle the load rejection and remain on their normal sources, it is assumed that the station loads of not more than half of the operating units would be instantaneously transferred to the $230 \mathrm{kV}$ system, i.e., a total load of $4 \times 75=300 \mathrm{MW}$, and that if effects of the system disturbance were prolonged, all seven units that may be affected could be reduced to a hot standby condition before all were placed on the $230 \mathrm{kV}$ system (if such transfer were deemed advisable). In that case the total load would be $7 \times 40=280 \mathrm{MW}$. Upon restoration of the system to normal and if hot standby station service loads have been transferred to the $230 \mathrm{kV}$ system, the loads are restored to the normal circuits as each generator is brought from hot standby back on line. Under these conditions, loads never exceed $280 \mathrm{MW}$. If the units are allowed to go into cold shutdown, the load on the alternate circuit would be: $7 \times 13=91 \mathrm{MW}$. With preheat of the first unit to be restarted, the load could be $100+(6 \times 13)=178 \mathrm{MW}$. After the first unit is back on line, the $500 \mathrm{kV}$ bus is re-energized (if not already done so by reconnection of 1 ines to the network) and the units can be restarted from their normal circuits. In such a case, load never exceeds $178 \mathrm{MW}$.

If a wide-ranging tornado should affect a 11 the 500 and $230 \mathrm{kV}$ lines to a plant, the generators (or at least two) could be kept at hot standby for up to 72 hours to feed all station loads through their normal circuits; or its station loads would have to be connected to the standby diesel generator source until the offsite system is restored.

Under NRC regulations the alternate station service circuit would need sufficient capacity for al1 20 units under cold shutdown: $20 \times 13=260$ MW.

A11 of these contingencies are believed to be of very low probability in the Hanford environment, and are judged to have the same probability of occurring as that determined for the cases of three to four simultaneously operating plant transfers developed above ("Estimate of Potential Station Service Load").

Based on our analyses of normal and abnormal operating conditions, we decided to use overal1 maximum demand of $360 \mathrm{MW}$ for purposes of system design, 
corresponding to a diversity factor between 3.33 and 4.17 . It would allow for the most severe conditions visualized for one group of six or seven units plus one unit in another group, running, or four to five units on cold shutdown in other groups.

Since the diversity factor of smaller groups of units, for example the four or five units in one 100p, would be less than 3.75 and since a diversity factor of 1.00 could be accommodated at $230 \mathrm{kV}$ without significant added investment in conductors, full capacity has been assumed to be provided in conductors and switches in such loops.

The above discussion assumes no central control. Control cannot be exercised over the failures causing automatic transfers of loads to the $230 \mathrm{kV}$ circuit. However, it can be exercised over (1) operation within the 72-hour period after one source is lost, (2) optional operation on the alternate circuit when the normal one is also available, and, (3) startup operations from the hot standby or cold shutdown condition. Dispatching control could assure that in the highly improbable event that load limits on the $230 \mathrm{kV}$ line are approached, the timing of operational moves could prevent overloading. However, at times of widespread emergency, a dispatching office should probably not be burdened with such controls, and it is believed that the proposed design basis capacity would eliminate any need for control.

\section{$230 \mathrm{kV}$ System Description}

The expected $230 \mathrm{kV}$ system in the 1990s is shown in Figure 7 . It will consist of:

1. Substations at Midway, Gable Mountain, Hanford, Ashe, and White Bluffs

2. Three lines between Midway and Gable Mountain. These are the current ERDA Hanford Loop lines and the Midway Scootney line.

3. Two lines between Gable Mountain and Ashe

4. Two lines between Ashe and White Bluffs

The principal source to the Hanford Area $230 \mathrm{kV}$ system is the Midway Substation. Midway is connected to the Priest Rapids powerhouse, Big Eddy, 


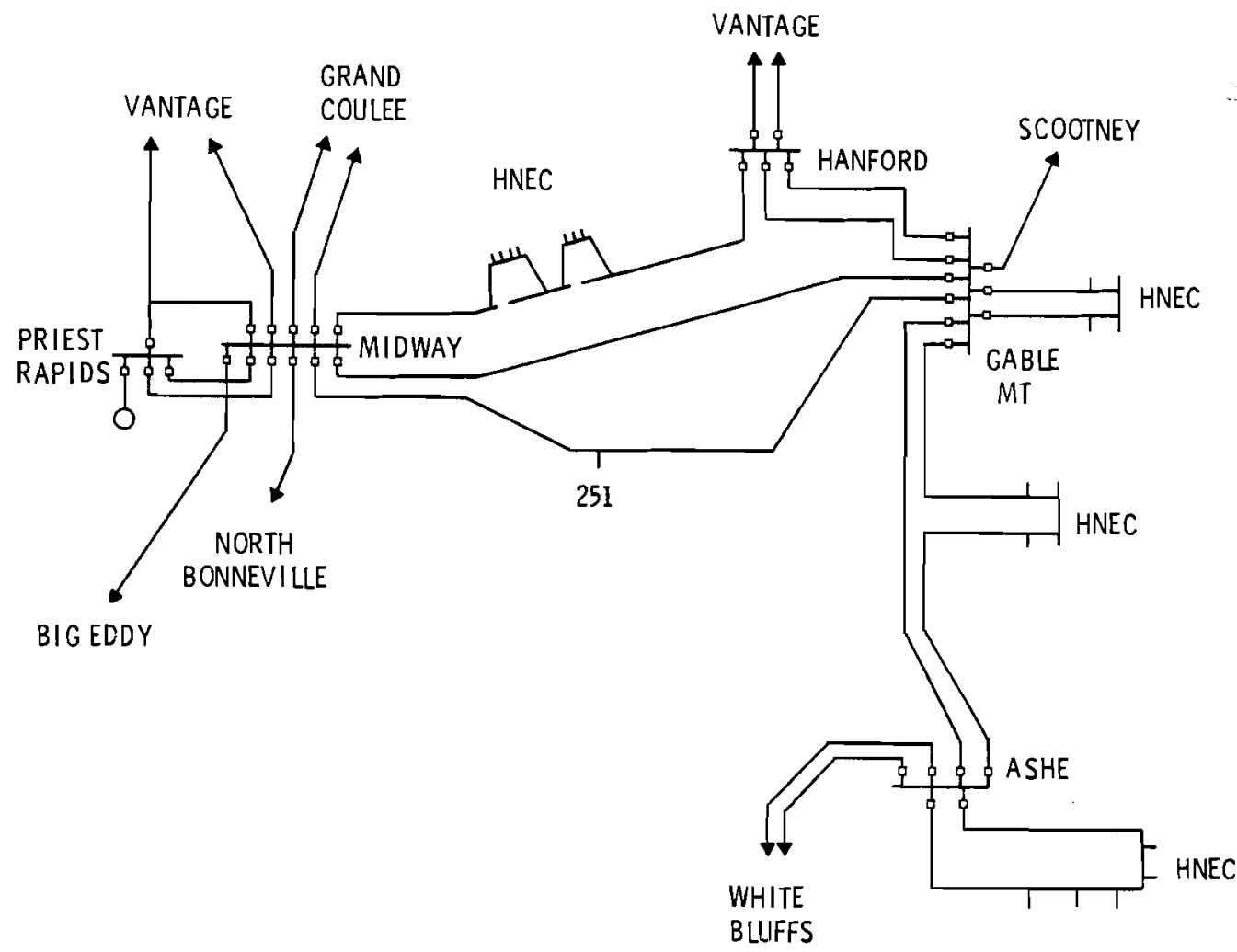

FIGURE 7. HNEC Switching Stations for (230 kV System) 20 Generating Units. Source of Station Service Power for Alternate Circuits, Concept A

Grand Coulee, Vantage and North Bonnevi1le. Power can also be supplied through the White Bluffs and Scootney connections from McNary and Ice Harbor dams even if the lines to Vantage are out of service.

The $230 \mathrm{kV}$ system will be connected to the $500 \mathrm{kV}$ system by autotransformers at Vantage, Grand Coulee and McNary.

Additions for $230 \mathrm{kV}$ Supply

The additional requirement of a 360-MW station service capacity for the HNEC will require reinforcement of the $230 \mathrm{kV}$ system, which could either be transformer additions or $230 \mathrm{kV}$ line Additions. Construction of two $230 \mathrm{kV}$ lines between Vantage and Hanford and a second $230 \mathrm{kV}$ line between Hanford and Gable Mountain provide the best system reinforcement. 


\section{Operation}

In concept $A$ a number of $230 \mathrm{kV}$ plant station service transformers would be connected to a loop from a $230 \mathrm{kV}$ station. The normal operating condition would be with the loop opened in the middle with about half the plants served from each end of the loop. With this connection, service to only half of the plants on the loop would be lost during a line outage. A faulted section could be quickly isolated with disconnect switches, and plants could be transferred from one section of the loop to the other. Analysis of the Projected 1990 System

A power flow study has been made which assumes 18 thermal generators installed in the Hanford area, with 15 peaking during a summer peak load condition. Although the study is shown as August 1989, loads and generation represent a more future condition (mid-1990s).

Initially, it was assumed that there could be $540 \mathrm{MW}$ of station service load on the $230 \mathrm{kV}$ system, split equally to three stations (Hanford, Gable Mountain and Ashe). Following a meeting with ERDA and PNL, the $230 \mathrm{kV}$ load was reduced to $360 \mathrm{MW}$, with this load occuring at any of the three stations, but not simultaneously.

Results of our analysis of the projected 1990 system are shown in the diagrams of Appendix $C$, and discussed below.

1. This much generation in the Hanford area results in excessively heavy line loadings from White Bluffs to McNary. Even the addition of a $230 \mathrm{kV}$ line between these stations does not unload the $115 \mathrm{kV}$ lines. Support now planned in the McNary and Franklin area makes it possible to open the Badger-Richland and Benton-Franklin lines to separate these two areas when overloads occur. Compare load flow diagrams $A 8929$ and A8931 (Appendix C).

2. The Midway bus is not a strong enough source for the amount of load supplied even with the lines between White Bluffs and McNary open. (See Diagram A8930, Appendix C). 
3. The Midway source may be strengthened in either of two ways. One proposal is to add a 500/230 kV bank at Ashe (Diagram A8929). A second proposal is to add additional $230 \mathrm{kV}$ lines from Vantage to the loop having the station service load (Diagram A8944). In case A8944, two $230 \mathrm{kV}$ Vantage lines were terminated at Hanford and a second $230 \mathrm{kV}$ line was added between Hanford, Gable Mountain and Ashe. This provides sufficient strength for a line outage with $360 \mathrm{MW}$ of station service load supplied on the $230 \mathrm{kV}$ system. The support from Vantage is favored since it used existing $500 / 230 \mathrm{kV}$ bank capacity at Vantage. It also has better reliability. Figure 8 shows an example of peak power flow in the Hanford vicinity for this method of system reinforcement.

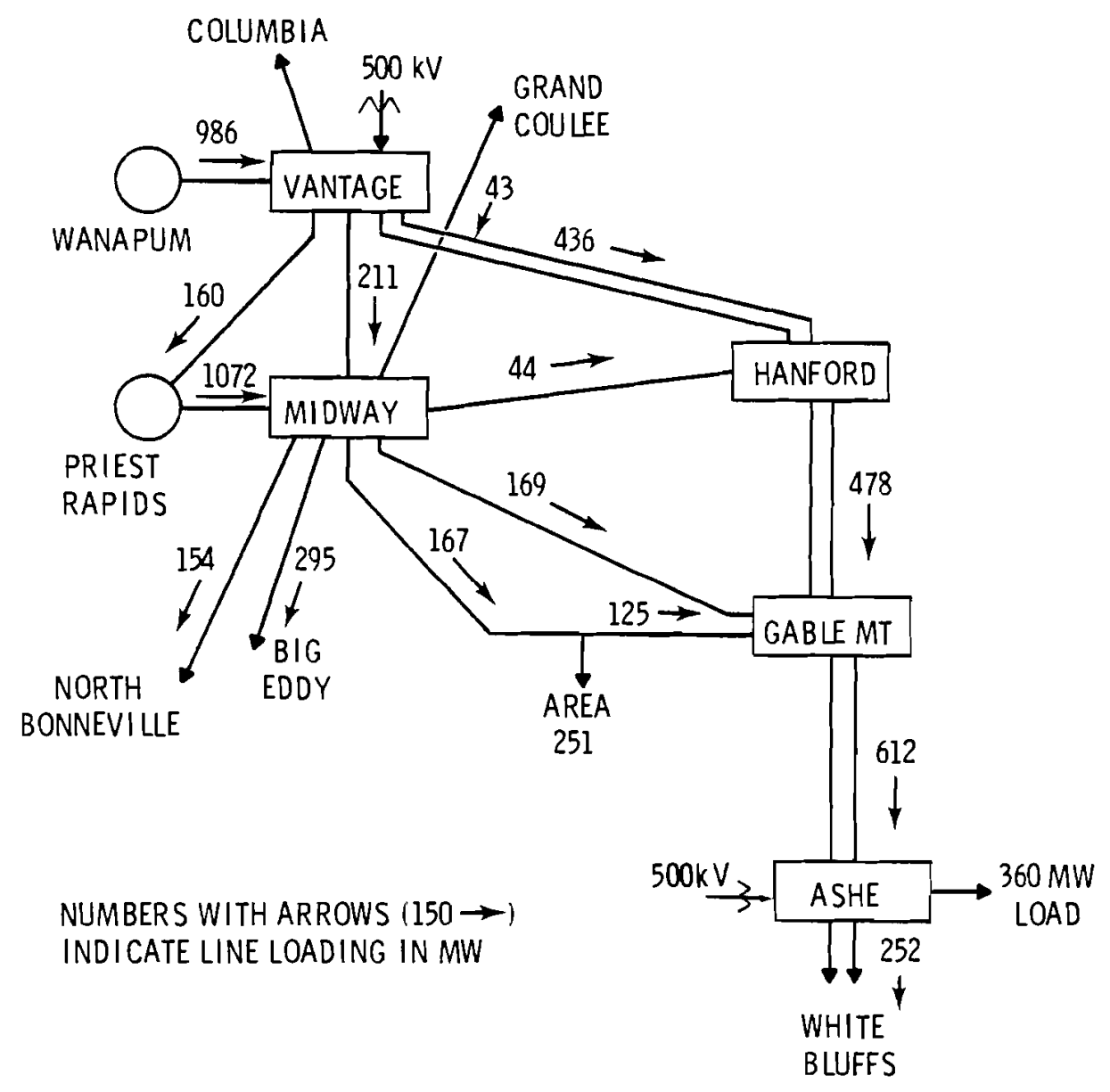

FIGURE 8. Hanford Area $230 \mathrm{kV}$ System with 360 MW Load at Ashe 
4. The Midway-Scootney $230 \mathrm{kV}$ line was also terminated at Gable Mountain in this study. This provides additional support not only for the station service load but also for the two $230 \mathrm{kV}$ lines to White Bluffs. This addition probably will be required before the extensive thermal plant development in the Ashe area. It is needed when the second $230 \mathrm{kV}$ line to White Bluffs is added.

The schedule of construction of the added lines necessitated by HNEC loads is such that one line from Vantage to Hanford would be in service in 1994 and one in 1997, and the additional line from Hanford to Fable Mountain would be in service in 1997. These plans are based on present planning assumptions; transmission requirements, of course, could change in the future.

\section{THE $500 \mathrm{kV}$ SYSTEM}

The $500 \mathrm{kV}$ system projected for the 1990s is shown in the map of Figure 3 and the diagram of Figure 9 . The $500 \mathrm{kV}$ circuit arrangement proposed for an HNEC shown in Figure 4 is taken from the referenced transmission study BNWL-B-426. This diagram shows six or seven units feeding into each of the three switching stations, and such an arrangement may be considered typical of an HNEC development, although it is still uncertain how many units should feed into one switching station. The required circuit breaker interrupting capacities may become too great, or, in the final analysis, concentrating that much capacity at one station may be unacceptable. A switching station adjacent to each three- or four-unit station may be attractive from an economic standpoint. However, this question need not be resolved for purposes of exploring station service alternatives.

The system will evolve to fill the export power needs of the mounting generating capacity at HNEC, as well as the growing loads in the eastern part of the region. The capacity of the $500 \mathrm{kV}$ system will not be affected by HNEC station service requirements under either Concept $A$ or $B$. In Concept $B$, station service power drawn from the system over the alternate circuit merely subtracts from the overall power exported through a switching station. In Concept $A$, power drawn by the alternate circuit would come from 


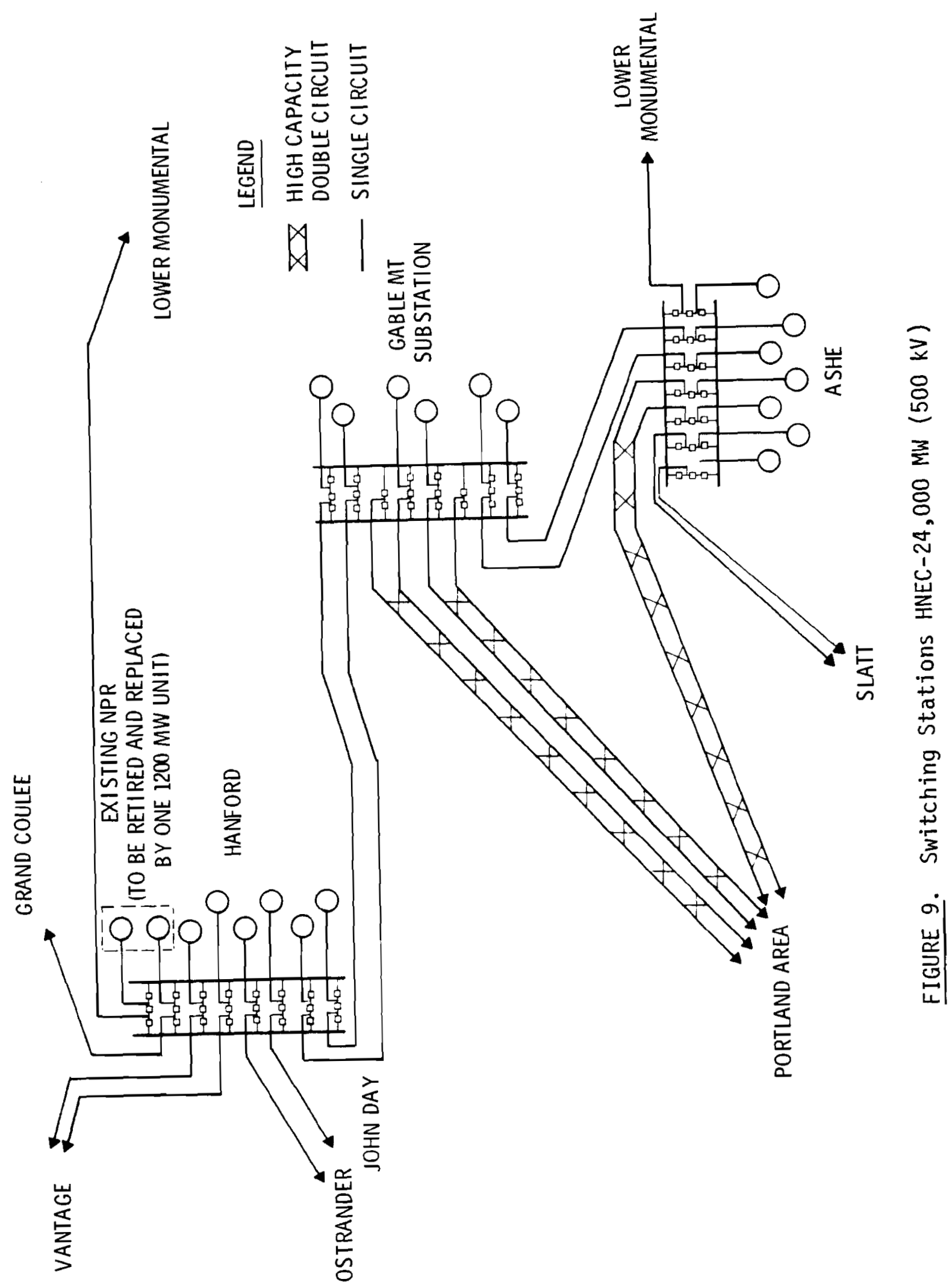


the $230 \mathrm{kV}$ system, which is interconnected with the $500 \mathrm{kV}$ system, but which would have little effect on $500 \mathrm{kV}$ system capacity insofar as HNEC loads are concerned. Therefore no incremental costs would be incurred on the $500 \mathrm{kV}$ offsite system by use of Concept B.

Although emphasis in the load-flow studies discussed under "Analysis of the Projected 1990 System" is on the $230 \mathrm{kV}$ system, the case studies cover the $500 \mathrm{kV}$ system as well. Incremental costs in the $500 \mathrm{kV}$ system due to export power transmission from HNEC were evaluated in the reference study. (1) Those results would not be altered by the use of either method of providing station service power. 
The technical and functional characteristics of the alternate circuits of the two concepts are compared in Table 1. The normal circuits are the same in both concepts.

\section{TABLE 1. Comparison of Technical and Functiona 1 Characteristics of Concept $A$ and Concept $B$}

Topic

Line and equipment exposure to

failure
Concept A

Has longer lines at higher voltage (230 kV vs $69 \mathrm{kV}$ ), and more underground cable at crossings with $500 \mathrm{kV}$ lines

Time to restore service after a failure
With shared circuits, probability of one or more plants being served from the al ternatie circuit at time of fault.

System stability
4-7 generating units are on a loop, but the loop is nomaliy operated open in the middle so that only half would be affected by an outage.

See Relative Merit.
Concept B

Has more apparatus (transformers and circuit breakers) than $A$
Overhead line failures are quickly repaired. Underground $230 \mathrm{kV}$ cable repair would require cable stock on hand for quick repair, but schedules can go beyond 72 hours because of the 1000 arrangement
A failure of the $500 / 69$ kV transformer could seriously affect the availability of two to four generating units if rapid repairs or re-

placement are not pro-

vided. Even though

the failure rate for such transformers is low, the loss of 4800 MW of capacity on the system in the rare event of such failure could be serious. Thus, cost estimate for Concept $B$ allows for a rail-mounted spare transformer, with capacity for four units, to be kept at HNEC for rapid transfer to an affected station. Spare $69 \mathrm{kV}$ cable is also necessary, since a failure in the radial circuit would require a 72 -hour repair.

3-4 generating units are on a $500 / 69 \mathrm{kV}$ transformer. Transformer failure would affect all. Line failure would affect only one.

See Relative Merit.
Relative Merit

Historical failure rate on these types of lines and apparatus is low in both concepts (Ref. 5,6). With a 72-hour grace period before forced shutdown, generator availability would be affected only if (a) the circuit cannot be restored within 72 hours, or (b) a plant is operating on the alternate circuit, its normal circuit having become unavailable less than 72 hours previously.

The exposure difference between concepts, per se, would make little difference in generating plant availability.

If provisions for restoring service within 72 hours are made as indicated, the two concepts would be approximately equal in their potential ef fect on generating plant availability.
Any failure on A could affect 2-4 units. Only a transformer failure on $B$ would affect more than one unit. Slight advantage for $B$.

The concepts seem equal with respect to the stability of $i$ ts source on the bulk power system. 


\section{Table 1 (continued 1)}

Topic

Generating sources on the network

Exposure to tornado or earthquake

Electrical separation of the normal and alternate circuits

Physical separation of the normal and alternate circuits

Line capacity in the network

Human error (inadvertent switch trip wrong relay setting)

Flexibility and quality of service during HNEC growth
Concept A

Hydro plants to the west will feed directly into the $230 \mathrm{kV}$ system and tie into the $500 \mathrm{kV}$ system at Vantage and McNary.

The $230 \mathrm{kV} 1$ ines follow same general route as $500 \mathrm{kV} l$ ines in and around HNEC. The $230 \mathrm{kV}$ switching stations in most cases would be in the same general areas as the $500 \mathrm{kV}$ station. northeast and south-

Concept B

Adjacent plants at HNEC, growing in number and at different locations as the center develops, will feed directly into the $500 \mathrm{kV}$ system and to the $230 \mathrm{kV}$ system via system autotransformer.

See Concept $A$.

Since one circuit is served from the $500 \mathrm{kV}$ system and one from the $230 \mathrm{kV}$ system, and since the closest points of interconnection of the two systems are at Vantage and McNary, $A$ has a greater degree of electrical separation.

Required physical separa- Separation is of concern tion of offsite lines can be maintained. Onsite lines would have separation at the closest points comparable to $B$. Underground cable would be used as required.

See The $230 \mathrm{kV}$ System. Planned capacity is judged adequate but regulatory position is unknown.

Error could affect more than one plant (see shared circuits, etc.)

Overhead loop lines can be changed or extended with relative ease, and with a constantly reliable service. The $230 \mathrm{kV} l$ ine capacity would have to be inpriate time to accomnodate the combined HNEC loads and flowthrough power. Lines are more exposed to construc tion interference than in Concept $B$.

The two circuits points of connection with the network are separated by $3 \mathrm{cir}$ cuit breakers, all are in the same switching structure. the plant.
Ample capacity for any combination of plant the network.

Error could affect only one plant. former and switchgear are located, Concept B is less flexible than $A$ to major siting changes. Reliability of service during growth stages is comparabie to that of Concept $A$. loads is inherent in

Once 500/69 kV trans-

Relative Merit

No difference is detected in the reliability of the network as affected by number and location of generating feed points.

Both systems can be served from the north or the south. If line sections are lost, the switching stations could be served from the opposite direction. If structures of both systems are equaliy resistant to the the forces, the effects of tornado or earthquake on generator availability or continuity of service to plant equipment would be equal. If entire switching stations are lost, safety loads would be transferred to internal generators in each case. Concept $A$ may have slight advantage in that if only a $500 \mathrm{kV}$ or a $230 \mathrm{kV} \mathrm{sta-}$ tion is lost, but not both, offsite service would still be available for safety (not operating) purposes.

A has greater degree of electrical separation than $B$, and one circuit would remain in service even if three relaying zones were involved in a cascading failure. Both concepts meet NRC requirements.

Separation is of concern Necessary physical separation can be only from the $500 \mathrm{kV}$ maintained in either concept - with some switching station into economic penalty to $A$ for underground crossings.

Capacity of both concepts is believed to be ample as proposed, but there is uncertainty as to regulatory requirements for Concept $A$. If capacity in lines of Concept $A$ has to be sufficient for all possible connected load, there would be a severe economic penaity.

Susceptibility to error is about the same for both concepts. Possible consequences are slightly greater for Concept $A$.

All interim requirements can be met with either concept. The initial installations in both cases must be designed to accommodate growth. 
Table 1 (continued 2)

\begin{tabular}{|c|c|}
\hline Topic & Concept A \\
\hline $\begin{array}{l}\text { Adaptability for } \\
\text { sporadic growth } \\
\text { rather than firm } \\
\text { scheduled growth of } \\
\text { an HNEC. }\end{array}$ & $\begin{array}{l}\text { Isolated plants and } \\
\text { plant built from time } \\
\text { to time in the absence } \\
\text { of an overall program } \\
\text { can be served under } \\
\text { Concept A without large } \\
\text { front-end investment. } \\
\text { A few plants can be } \\
\text { accomodated by the } \\
230 \mathrm{kV} \text { grid with reserve } \\
\text { capacity so that any re- } \\
\text { inforcement chargeable } \\
\text { to such plants would be } \\
\text { many years in the } \\
\text { future. }\end{array}$ \\
\hline $\begin{array}{l}\text { Environmental } \\
\text { impact. }\end{array}$ & $\begin{array}{l}\text { Grid reinforcements of } \\
55 \text { to } 60 \text { miles of } \\
230 \mathrm{kV} \text { transmission } \\
\text { line in and north of } \\
\text { the Reservation, with } \\
\text { added visual land-use } \\
\text { and other impacts from } \\
\text { such lines. }\end{array}$ \\
\hline
\end{tabular}

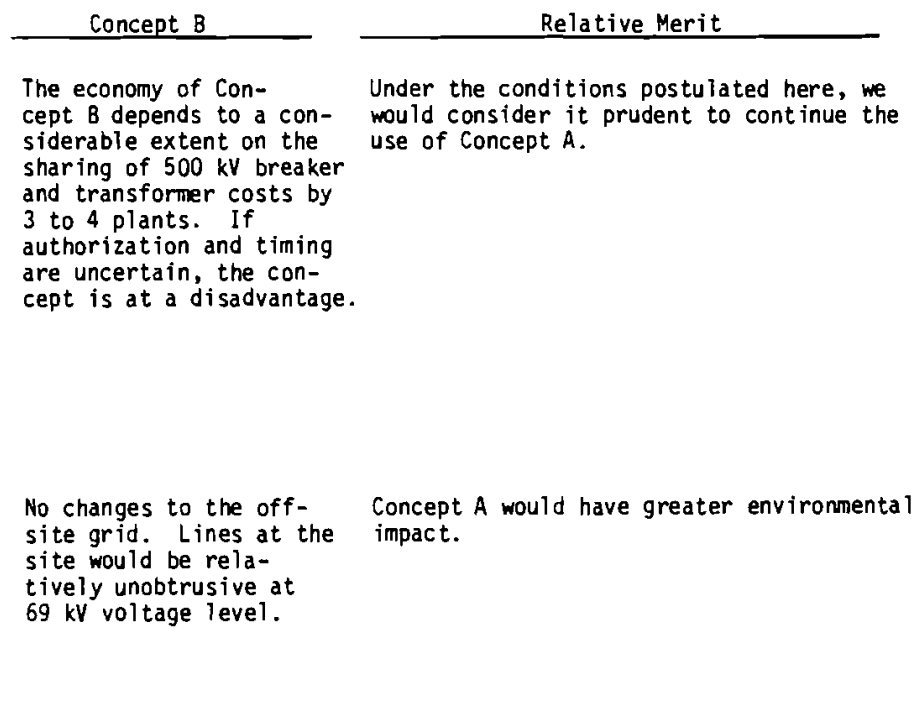

ACCESS TO THE GENERATING PLANTS

The comparative difficulties of transmission line access to the generating plants under each concept are illustrated in Appendix D. The major questions to be resolved are: How much underground 230 or $69 \mathrm{kV}$ cable would be necessary at crossings with $500 \mathrm{kV}$ lines, and how might the overhead and underground 1 ines be affected by the configuration of plants in a group? The rough maps in Appendix $D$ indicate the comparative requirements, and were used as a basis for comparative cost estimates.

Note that the open arrangement of the Ashe group involves less crossings, but more overhead line, in the $230 \mathrm{kV}$ 10op of Concept $A$ than do the more compact arrangements of the two-, three-, and four-unit groups of Gable Mountain and Hanford.

It is assumed that line crossings of the 500 and $230 \mathrm{kV}$ circuits would be made with the $230 \mathrm{kV}$ circuit underground if the loss of both lines, together with a crucial circuit breaker malfunction were to cut off both the normal and the alternate station service supplies to a generating plant.

In the future there will be numerous crossings of $500 \mathrm{kV}$ and $230 \mathrm{kV}$ lines on the Hanford reservation or near it. By the year 2000 there could be from 25 to 30 such crossings whether or not Concept A were used for HNEC station 
service. However, most of these crossings are not included in the above assumption; that is, loss of the two lines and malfunction of the most crucial breaker would not cut off all offsite station service to any generating unit. Therefore, the cost estimates to follow later in the report do not include the cost of placing these remote crossings underground.

\section{COMPARATIVE COST EST IMATES}

Cost estimates are limited to the equipment and lines used solely for station service and the cost of $230 \mathrm{kV}$ transmission additions allocated to HNEC station service loads (Concept A). The costs are incremental to those of the main generator power circuits to which they are attached, and they are in 1975 dollars.

The construction scheduTe of plants at the various sites throughout the HNEC could affect the relative economic merit of one form of station service supply over another. Best economy in the construction of generating plants at a center is achieved when the startup of successive plants at one general site is spaced about one year apart, (7) although some overlap in startups might occur in different groups. For purposes of this economic comparison the following construction schedule is assumed (Table 2).

This cost comparison includes (1) capital investment cost at the site, (2) costs of reinforcing the BPA system to support the HNEC incremental load and (3) consideration of differential operating costs.

\section{Capital Investment at the Site}

Since cash outlay must precede in-service dates for both transmission lines and plant facilities by about 3 years on the average, the series of payments would begin in 1984 and continue through 1997. A breakdown of the total investment in station service facilities for 17 units (excluding the three now committed) is shown in Table 3 .

Costs of BPA System Reinforcement

Concept $B$ has no costs in this category since any power flow from the network to station service loads is over lines and transformers required for outward flow of generated power. 
TABLE 2. Plants Beginning Commercial Operation

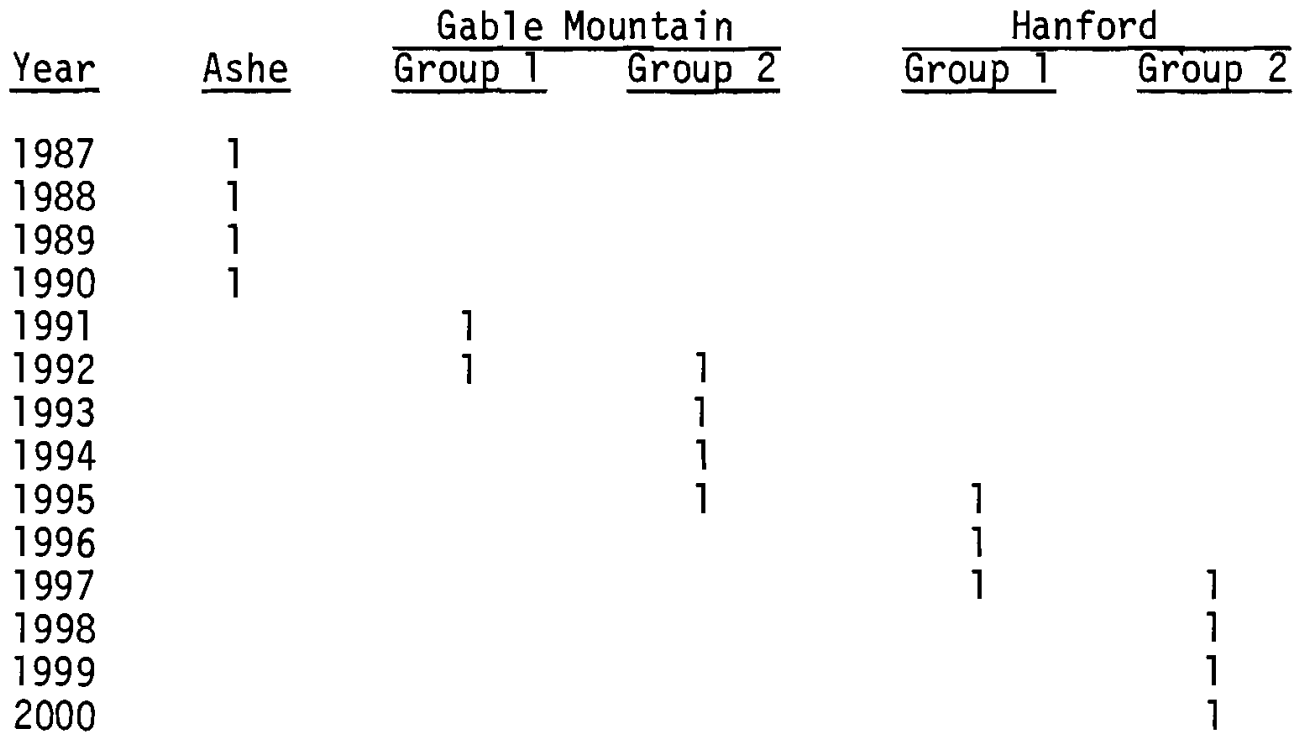

TABLE 3. Investment in Station Service

Facilities (millions of dollars)

Concept A Concept B

Normal Circuit

Ashe group, 4 added units

6.2

6.2

Gable Mt group, 6 units

9.4

9.4

Hanford group, 7 units

10.9

$\underline{10.9}$

26.5

26.5

Alternate Circuit

Ashe group

9.9

12.2

Gable Mt group

16.3

16.8

Hanford group

17.4

19.7

Spare transformer

TOTAL

$\frac{--}{43.6} \quad \frac{4.0}{52.7}$


To determine reinforcement costs for Concept $A$ that should be attributed to HNEC loads is complicated by growth of power transfer over the $230 \mathrm{kV}$ lines through the area; by temporary excess capacity in portions of the system even under the best overall solution to the problem of accommodating growth; and by the imposition of an estimated demand of $225 \mathrm{MW}$ on the $230 \mathrm{kV}$ system by the three plants already committed. This demand is imposed regardless of whether any additional plants are built or whether Concept $A$ or $B$ is used for the 17 plants to follow.

As noted in "Additions for $230 \mathrm{kV}$ Supply," the system reinforcements made necessary by a 20-unit HNEC would consist of 55 to 60 miles of $230 \mathrm{kV}$ line in three sections. The cost of these lines and their terminal apparatus has been estimated at $\$ 8.0$ million. Part of the line construction would be in service in 1994 and part in 1997.

These system additions would not be needed earlier, even though the three plants already committed with a possible demand of 225 MW would be in operation as early as 1984. Capacity is expected to be available in the system during that interim period without any reinforcement specifically required for an HNEC.

The full costs of the system reinforcements are charged to Concept $A$ rather than allocated between the three plants already committed and the 17 plants that would follow in an HNEC program; the rationale is that the reinforcements are not needed during the 1985-2000 period for committed plants but would be needed for the full-scale HNEC. Since the investment requirement comes rather late in the period, it has a relatively minor effect in a comparison of discounted present worth of investment costs of the two concepts.

In an overall economic sense, the allocated costs would be added to the other capital costs of Concept $A$; however, in actuality the costs would be incurred by BPA rather than by HNEC owners and would be recovered by BPA through wheeling or other service charges billed to the owners. The degree to which the incremental reinforcement costs are reflected in the charges would depend on contractual or rate-making policy and practice. 
Timing of the Investment Requirements

Figure 10 illustrates the effect of timing of investment requirements. In Concept $B$ the spare transformer must be available at the beginning of the period of HNEC expansion. In Concept $A$ the allocated investment in offsite transmission system comes late in the period for reasons discussed in the preceding section.

The discounted present worth (at the beginning of the development period) of investments in the alternate circuits over the period is given in Table 4 for discount rates of $0,5 \%$ and 10\%. The "front-end cost" effect is greater for Concept B, thus increasing Concept B's disadvantage as the discount rate increases.

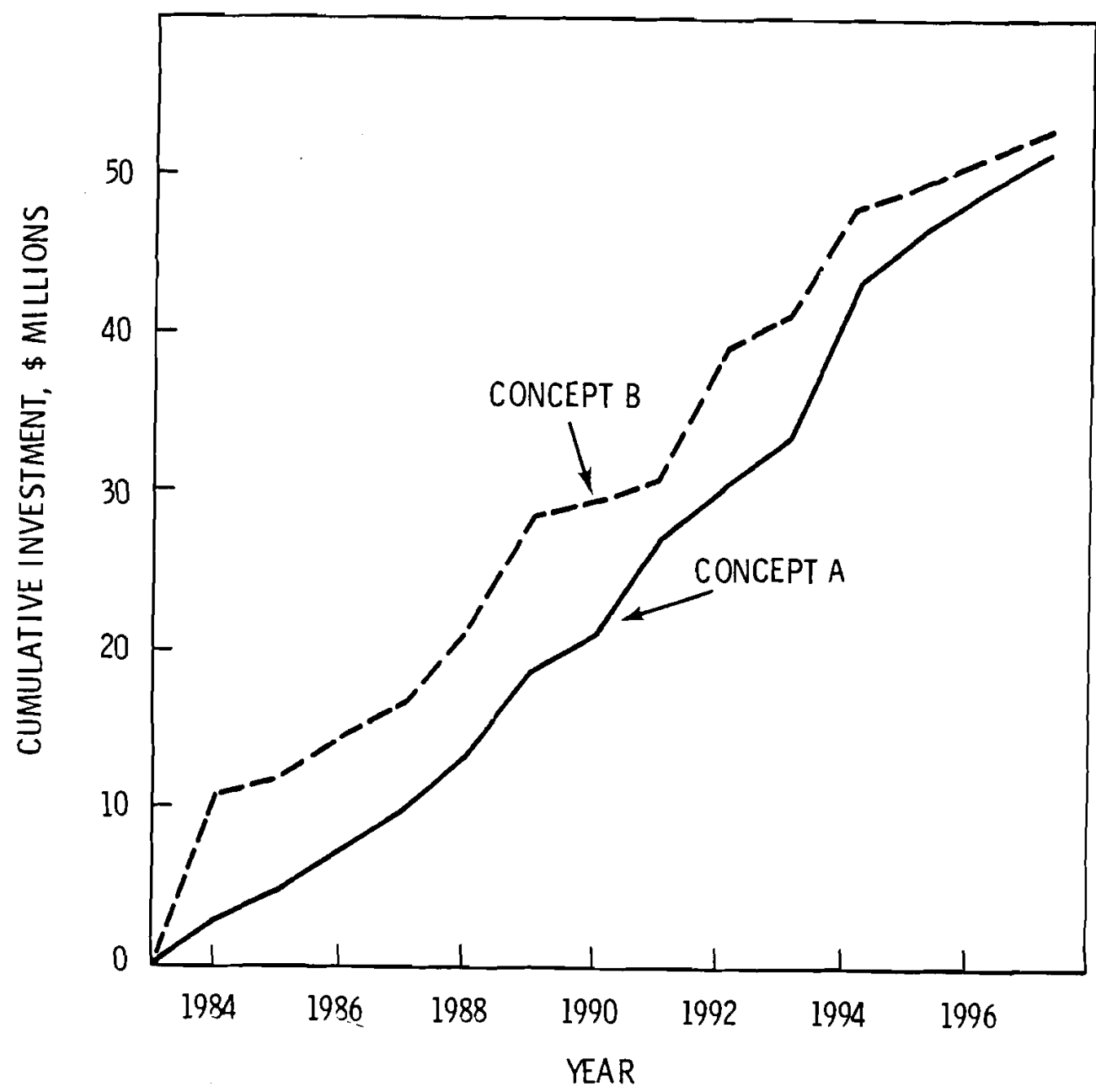

FIGURE 10. Estimated Cumulative Investment in Alternate Circuit Station Service Lines and Equipment 
TABLE 4. Discounted Present Worth of Alternate Circuit Investments (miliion dollars)

Concept A

Concept B

Ratio A/B

\begin{tabular}{cccc}
\multicolumn{3}{c}{ Discount Rate } \\
\hline 0 & & $5 \%$ & $\frac{10 \%}{28.2}$ \\
\hline 51.6 & & 37.3 & 28.2 \\
52.7 & 41.0 & 33.3 \\
0.98 & 0.91 & 0.85
\end{tabular}

The capital investment estimates show that:

1. The total investment requirement for 17 new generating units would be approximately equal for the two concepts, but the discounted present worth of the required investment would be for 10 to $15 \%$ less for Concept $A$.

2. Underground cable sections at crossover points comprise about $16 \%$ of the onsite investment of Concept $A$, but only about $8 \%$ of that of Concept $B$, which tends to penalize Concept $A$. The routing of $230 \mathrm{kV}$ lines and the placement of $230 \mathrm{kV}$ switching stations so as to reduce the underground requirements would narrow the difference, but not equalize the undergrounding requirements of the two concepts.

3. The costs of Concept $A$ at Ashe are favorable because (a) part of the system would already be in place, and (b) the assumed placement of plants is more dispersed and open, thus requiring no additional underground transmission cable.

4. The normal station service supply circuit, which is the same for both concepts, involves about half the investment required for the alternate circuits.

Operating Cost

The only significant difference in operating cost between the comparative concepts is in no-load transformer losses. In Concept $A$ the voltage is transformed from 230 to $6.9 \mathrm{kV}$ in one step; in Concept B from 500 to $69 \mathrm{kV}$, 
then from 69 to $6.9 \mathrm{kV}$. The $500 \mathrm{kV}$ transformer of Concept B would usually carry little or no load but would be energized. A comparison of no-load losses shows a balance of about 900 kilowatts chargeable to concept $B$ in a fully developed center. When the demand and energy losses are valued on the basis of cost to generate in new facilities, the penalty to concept $B$ would rise to $\$ 120,000$ per year in 1996 . This is only about one percent of the fixed charges on capital investment in the circuits at that time and may be ignored.

\section{OTHER CONCEPTS}

In addition to Concepts $A$ and $B$, other combinations of normal and alternate circuits from the offsite system were considered. After an exploratory examination they were found to be unattractive in the HNEC situation, but merit brief discussion.

1. A system whose normal and alternate circuits originate at the $500 \mathrm{kV}$ bus. The economics of this concept were disadvantageous; $\$ 25$ million in additional investment would be required without compensating benefits in reliability for 17 future units.

2. A system whose normal circuit originates at the $500 \mathrm{kV}$ bus, as in Concept B and alternate on the $230 \mathrm{kV}$ system as in Concept A. This concept also proved economically unattractive, averaging $\$ 25$ million in additional investment without compensating benefits.

3. A concept with a separate generating station to serve as an alternate offsite source for multiple plants. ${ }^{(8)}$ This concept would provide maximum independence between the two offsite sources. A gas turbine was considered for the generating source since it would be carrying no load for most of the time, although it would have to be prepared to supply load within a few seconds under certain contingency conditions. 
If the separate system were designed to provide the capacity being considered for the $230 \mathrm{kV}$ system at Hanford, i.e., $360 \mathrm{MW}$, it could be ruled out for the following reasons.

- Transmission from the generating station would probably have to be at $230 \mathrm{kV}$, and the investment in 1 ines, circuit breakers and transformers would be approximately the same as for the alternate BPA $230 \mathrm{kV}$ system with no benefits to offset added costs.

- The fixed charges on the generating plant investment and on the standby operating costs would add about $\$ 1$ million per year per reactor plant (in 1975 dollars), with no substantial compensating benefits. In effect, the generating capacity would be a duplication. Not being tied in with the BPA system, it could not be considered for peaking service (although a tie-in would not be ruled out on the basis of safety).

If such a system were designed to provide for only the critical station loads, transmission and distribution at a lower voltage may be feasible and the concept might be more attractive in a comparison with other schemes. However, providing only such minimum coverage and flexibility would run contrary to current practice by most utilities.

4. Use of three offsite circuits instead of two. Some utilities choose to use three circuits qualifying as "offsite circuits," even though the third is not required by NRC. This concept has the advantage of providing for unrestricted plant operation in the event of a prolonged outage on one of the station service supply circuits, such as an outage involving transformer replacement. One architect engineer has a standard design using three offsite circuits, two of which are tied to the station buses served alternately by two diesel generators of the onsite system, and one tied to the third bus for 
non-critical station loads. The flexibility provided by such a system may justify the cost, especially if the offsite circuits are tied to a relatively low-voltage system $(69 \mathrm{kV})$.

Should the utility want a third offsite source for the HNEC situation, combinations of the concepts described above or duplications of Concepts A or B would be possible. The $230 \mathrm{kV}$ system would have two parallel 1 ines from the principal source (Midway) to the vicinity of the site areas, which possibly could be connected so as to give added security to dual $230 \mathrm{kV}$ station supply circuits. However, in the HNEC situation the added value of such redundancy did not justify the added cost in the opinion of the authors.

5. One of the two off site circuits with capacity for only safety loads. Such a system would comply with prior NRC requirements but would lack operating flexibility, and raise the question of whether an immediate forced shutdown (rather than a shutdown after 72 hours) would cost the utility enough to pay for added capacity in the al ternate circuit? The scope of this study does not include investigation of this question, but modern practice runs contrary to load shedding for loss of either offsite station service circuit, and the concept was rejected for that reason.

6. The following alternative applies only where the main generator bus is bifurcated, i.e., connected to two half-capacity transformers through two circuit breakers, such as in the plant designs of the McGuire, Perkins and Cherokee Stations of the Duke Power Company. A schematic drawing of such an arrangement is shown in Appendix $B$. Each of the two station service (offsite) circuits is taken from one side of the forked bus. The cost of such a system would be substantially less than those of the stations studied herein having conventional bus arrangements, and its lack of exposure is excellent.

The bifurcation designs provide a sufficient degree of electrical separation between the two circuits and presumably meet NRC 
requirements in that they provide for continuity of service in one circuit in the event of failure in one of the three zones and failure of one breaker to open. The number of intermediate zones is not as great as in Concept $A$ and $B$ for conventional bus arrangements, but since very few plant designs incorporate the bifurcated bus, further analysis of the station service possibilities was not undertaken. 


\section{RESULTS OF ANALYSIS}

The principal findings of our analysis are:

- The "normal" offsite circuit chosen for both comparative concepts, i.e., a circuit tapped from the generator bus at a point that can be isolated from the generator by a load-break switch, is confirmed as a preferred source of station power from functional, safety, and economic points of view. This applies to either dispersed plants or plants concentrated at a center. Alternative methods need be considered only for the "alternate" offsite circuit.

- The problems of providing an adequate alternate station service supply to an HNEC are similar to those of supplying service to three- and four-unit aggregations at other sites, several of which are in the planning stage; the difference is in the estimation of load diversity on a common transmission system (not directly connected with the bulk power system for the stations) serving several groups of plants, as would the $230 \mathrm{kV}$ transmission system of Concept $A$.

- The restraints on operation of the generating plant when one of the station service circuits is unavailable, plus a policy of always using the "normal" circuit when it is available, limit the use of the alternate circuit to the extent that a design diversity factor of 3.75 could apply to a group of 20 operating plants. A $360 \mathrm{MW}$ capacity in the system serving the group is estimated to be sufficient for any normal or abnormal combination of station service loads.

- With Concept A the BPA $230 \mathrm{kV}$ system would be reinforced to provide sufficient additional capacity for possible station service loads at HNEC. Load-flow studies indicate that the best way of reinforcing the system is to add two lines between Vantage and Hanford, and one line from Hanford to Gable Mountain. These lines would add to the visual impact on the environment. With Concept $B$ no changes would be required in either the $500 \mathrm{kV}$ or $230 \mathrm{kV}$ offsite transmission system. 
- Assuming they are properly designed, either of the two concepts studied in detail, Concept $A$ drawing from the reinforced $230 \mathrm{kV}$ system and $B$ drawing from the $500 \mathrm{kV}$ system at the three major switching stations at the center, could meet NRC safety requirements and the ordinary requirements of operating utilities for reliability and flexibility.

- A comparison of the two concepts revealed no significant difference between them with respect to equipment failure rates, exposure to natural hazards, effect of human error, and degree of physical and electrical separation from the circuits of the normal supply system.

- Estimated costs of the two concepts were roughly comparable. The "front-end" cost effect was more pronounced for Concept $B$; thus the discounted present worth of Concept $A$ 's costs was somewhat lower than that of Concept B. In both cases the differences were within the margin of accuracy of the estimates. The estimates depend to some extent on the geographical arrangement of generating units and switching stations, but are not extremely sensitive to those conditions.

- Other methods and combinations of methods of supplying station service power to a nuclear center were considered. Although most of them were acceptable from a safeguards standpoint, their value to a plant operator did not appear to justify added costs. Where a plant design has a bifurcated generator bus, station service could be drawn from each of the two buses reliably and economically. 


\section{REFERENCES}

1. Electric Power Transmission for a Hanford Nuclear Energy Center. BNWL-B-426, Battelle, Pacific Northwest Laboratories, Richland, WA, September 1975.

2. Nuclear Regulatory Commission Safety Guide 6, Independence Between Redundant Standby (On-Site) Power Sources and Between Their Distribution Systems.

3. Nuclear Regulatory Commission, RG 1.32 Rev. 1 Section c.1.a, Comment Issue.

4. William Feller, An Introduction to Probability Theory and Its Applications. John Wiley and Sons, New York, pp. 137-138, November 1966.

5. Report on Equipment Availability for the Ten-Year Period 1965-1974. EEI PubTication No. 75-50, November 1975.

6. Equipment Availability, Fossil, Component Cause Sunmary Report. EEI Equipment Availability Task Force of the Prime Movers Committee, 1973.

7. U.S. Nuclear Regulatory Commission, NUREG-0001, Nuclear Energy Center Site Survey - 1975, January 1976.

8. Alexander Borst, Standby and Emergency Power Supply of German Nuclear Power Plants. IEEE Transactions, Volume PAS-95, No. 4, July/August 1976. 


\section{ACKNOWLEDGEMENTS}

Information on BPA transmission lines and switching stations; reinforcements necessary to accommodate HNEC loads as indicated in load flow studies; current estimates of procuring and installing various elements of the transmission system; and opinions as to the dependability and stability of the network, were provided by the Bonneville Power Administration through J. R. Harries of the Transmission System Planning Department.

Information on WPPSS plants and engineering practices, and on utility interpretations of regulatory requirements in certain hypothetical situations was provided by the Washington Public Power Supply System through Dave Thonn of the Electrical Engineering Department.

The authors are indebted to Lonnie Foley for her careful editing of the report. 


\begin{abstract}
APPENDIX A
List of Acceptance Criteria for Electric Power

Applying to Offsite Circuits

for Station Service Power

Extracted from NUREG-75/087

Standard Review Plan

USINRC, Office of Nuclear Reactor Regulation

November 24, 1976
\end{abstract}




\section{TABLE A-1. Acceptance Criteria for Electric Power}

\section{Criteria}

1. 10 CFR Part to
a. 10 CFR $\$ 50.34$
b. 10 CFR $\$ 50.36$
c. 10 CFR $\$ 50.55 \mathrm{a}$
Contents of Applications: Technical Information
Technical Specifications
Codes and Standards

2. General Design Criteria (GDC), Appendix A to 10 CFR Part 50
a. GDC-1
b. $G D C-2$

c. $G D C-3$

d. GDC-4

e. $G D C-5$

f. $G D C-13$

g. $\mathrm{GDC}-17$

h. GDC-18

i. $\mathrm{GDC}-21$

j. $\quad G D C-22$

3. Institute of Electrical and Electronics Engineers (IEEE) Standards:
a. IEEE Std 279-1971
(ANSI N42.7-1972)
b. IEEE Std 308-1971

Title

Quality Standards and Records

Design Bases for Protection Against Natura 1 Phenomena

Fire Protection

Environmental and Missile Design Bases

Sharing of Structures, Systems, and Components

Instrumentation and Control

Electric Power Systems

Inspection and Testing of Electrical

Power Systems

Protection System Reliability and Testability

Protection System Independence
Criteria for Protection Systems for Nuclear Power Generating Stations

Criteria for Class IE Electric Systems for Nuclear Power Generating Stations 
TABLE A-1. (Continued)

Criteria

c. IEEE Std 352-1972

(ANSI N41.4)

d. IEEE Std 379-1972

(ANSI N47.2)

e. IEEE Std 450-1972

4. Regulatory Guides (RG)
a. $R G 1.6$
b. $\mathrm{RB} 1.32$
c. $\mathrm{RG} 1.53$
d. RG 1.75
e. $R G 1.93$

5. Branch Technical Positions (BTP) EICSB

a. BTP EICSB 11
Title

General Principles for Reliability Analyses of Nuclear Power Generating Station Protection Systems

Guide for the Application of the Single Failure Criterion to Nuclear Power Generating Station Protection Systems

Recommended Practice for Maintenance, Testing and Replacement of Large Stationary Type Power Plant and Substation Lead Storage Batteries

Independence between Redundant Standby (Onsite) Power Sources and between Their Distribution Systems

Use of IEEE Std 308-1971, "Criteria for Class IE Electric Systems for Nuclear Power Generating Stations"

Application of the Single-Failure Criterion to Nuclear Power Plant Protection Systems

Physical Independence of Electric Systems

Availability of Electric Power Sources

Stability of Offsite Power Systems 
APPENDIX B

Schematic Arrangements for Offsite Station Service Circuits of Threeand Four-Unit Nuclear Plants, from Preliminary Safety Analysis Reports for the Respective Projects. 
The safety and operational requirements for station service have been met in various ways in multi-unit plants or plant groups. Nine examples of schematic arrangements currently in use or proposed are given herein.

The example schematic arrangements (Figures B.1 through B.9) indicate two basic differences in design of offsite station service systems:

(1) The point at which the circuits from the offsite power system tie in with the network, and

(2) The number of generating units sharing the same buses, lines, or transformers serving station loads.

Options for point of connection with the network (tie-in point) include:

(1) The generator output circuit $(24 \mathrm{kV})$ with a generator load break switch as for the Hanford 1 and 4 and Hartsville designs.

(2) The same 230 or $500 \mathrm{kV}$ bus to which the generator is connected (e.g., designs for North Anna, Palo Verde, generator No. 1 at Alan Barton, and generator No. 1 at Shearon Harris).

(3) A separate station generator bus in the same switchyard, but at lower voltage (e.g., three generators at Alan Barton and two at Shearon Harris).

(4) Switching stations or lines in the vicinity, usually at voltage less than that of the bulk transmission system into which the generator feeds. The switching stations may either not be interconnected at the generator switching station or may be interconnected through an autotransformer (e.g., Hanford 1, 2, and 4, Hartsville, Alvin Vogtle, three generators at Alan Barton, and two at Shearon Harris).

The degree to which the various components of the circuits from the offsite power system are shared by other generating units is indicated in Table B-1. In this respect the most conservative design is that of Hartsville; that is, it has three circuits to the network. Otherwise, the 
only conciusion to be drawn from the table is that it is common to have four generator units share station service supply circuits. The switching arrangements of current designs have differing degrees of flexibility. The amount of capital that a utility can afford to invest in added station service flexibility depends on the flexibility and reserve capacity already in the system to which the new generating unit is being attached.

We assumed that capacity in all alternate offsite circuits in these examples, except for the $115 \mathrm{kV}$ circuit of Hanford 2, is sufficient for al1 possible connected loads.

The schematic drawings do not show the differing geographical distances between points at which the normal and alternate sources join the bulk power network. Some circuits tie in at the station switchyard, others at points up to 50 miles from the site. 
TO NETWORK

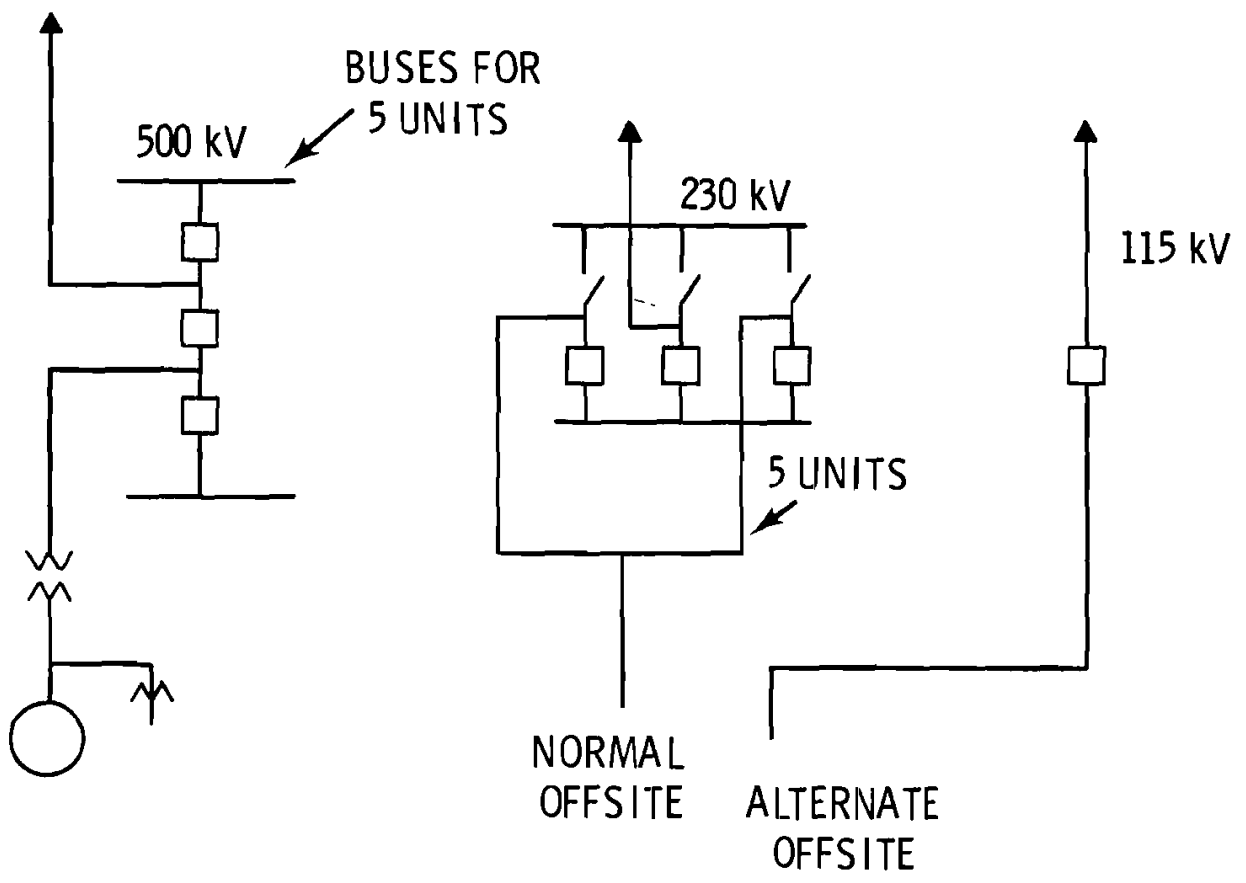

FIGURE B. 1. Hanford No. 2

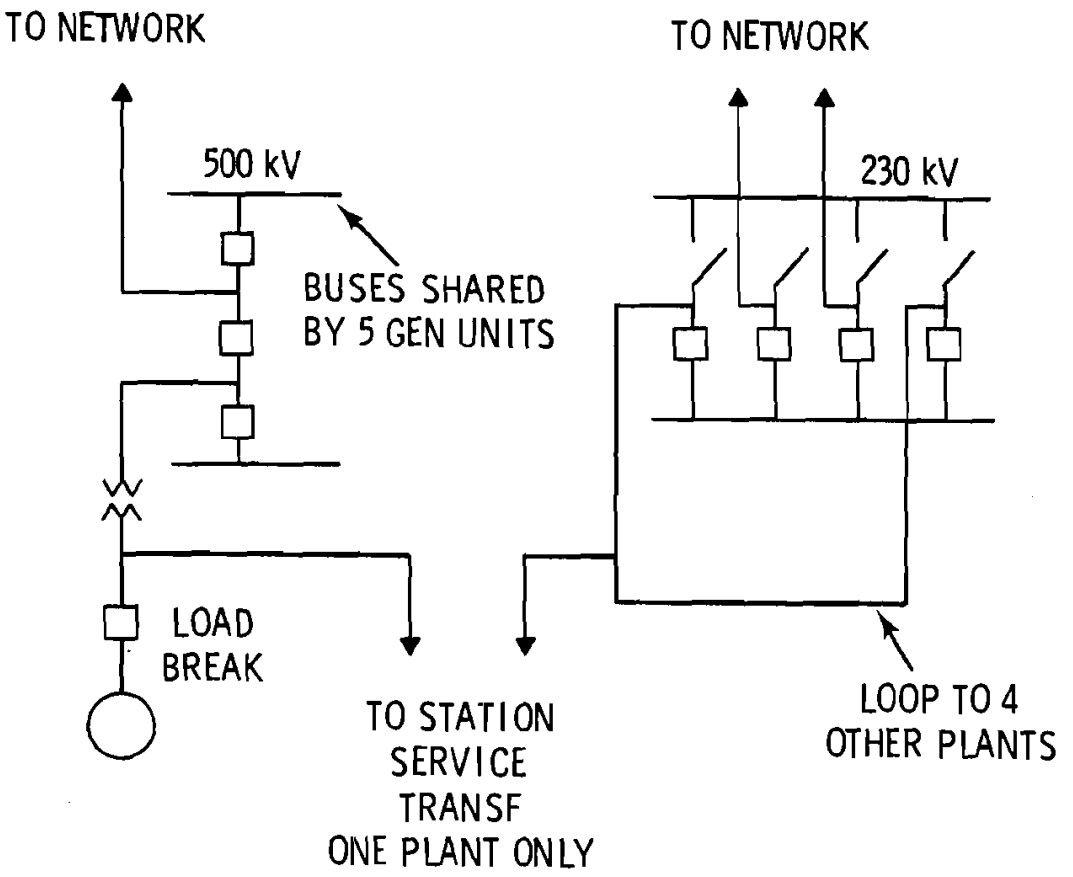

FIGURE B.2. Hanford No. 1 and 4. 
TO NETWORK
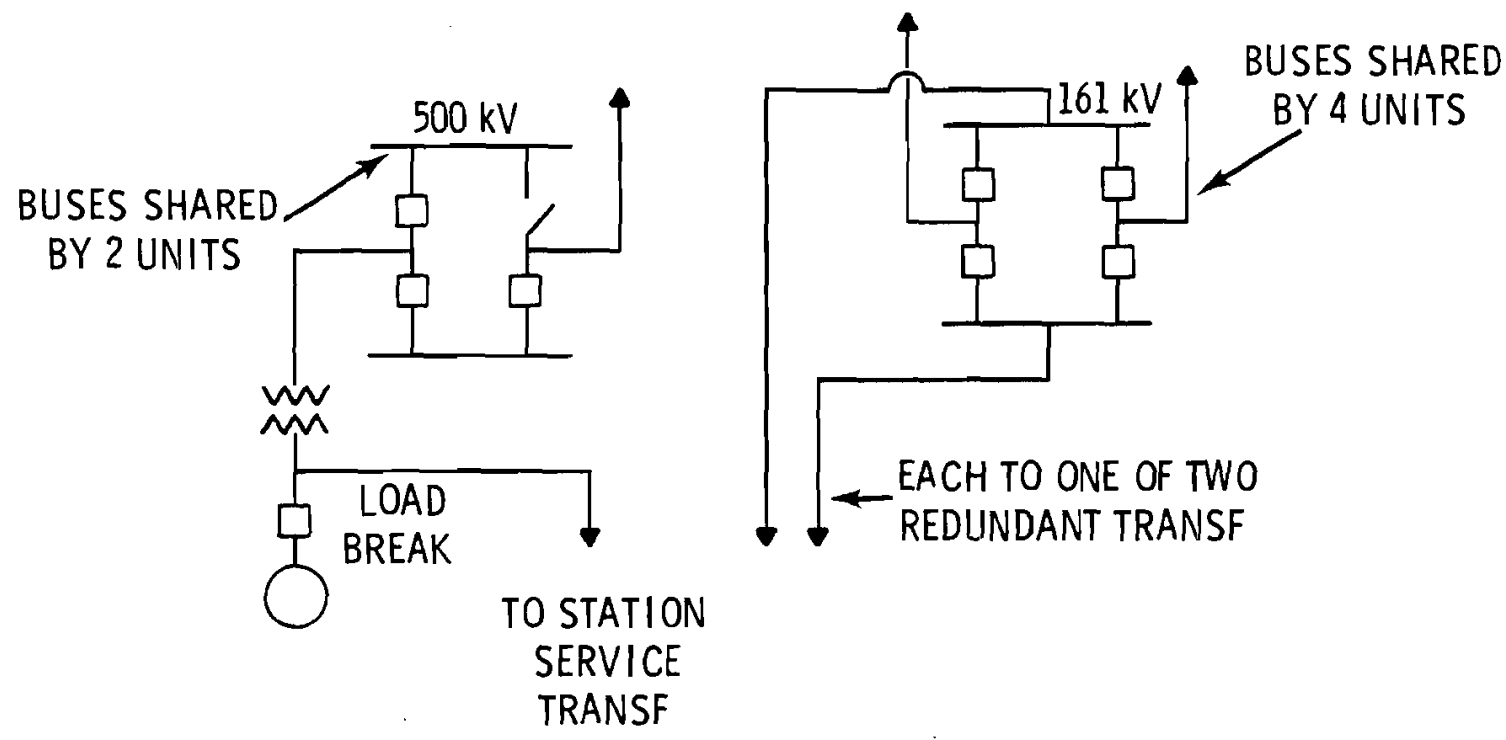

FIGURE B.3. Hartzville - 4 Units

TO NETWORK

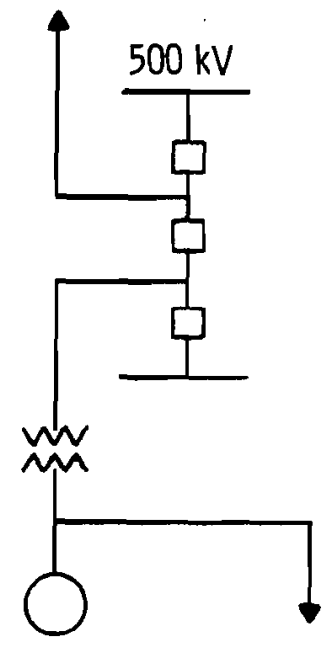

TO STATION SERVICE

TRANSF

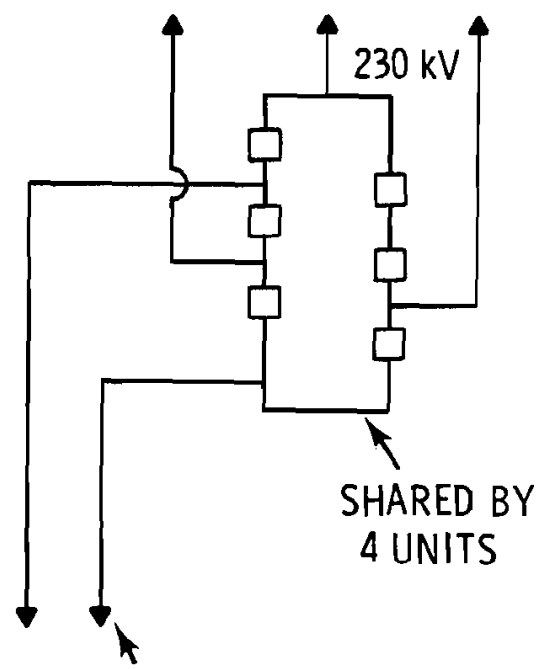

EACH TO ONE OF TWO REDUNDANT TRANSF

FIGURE B.4. Alvin Vogtle - 4 Units 


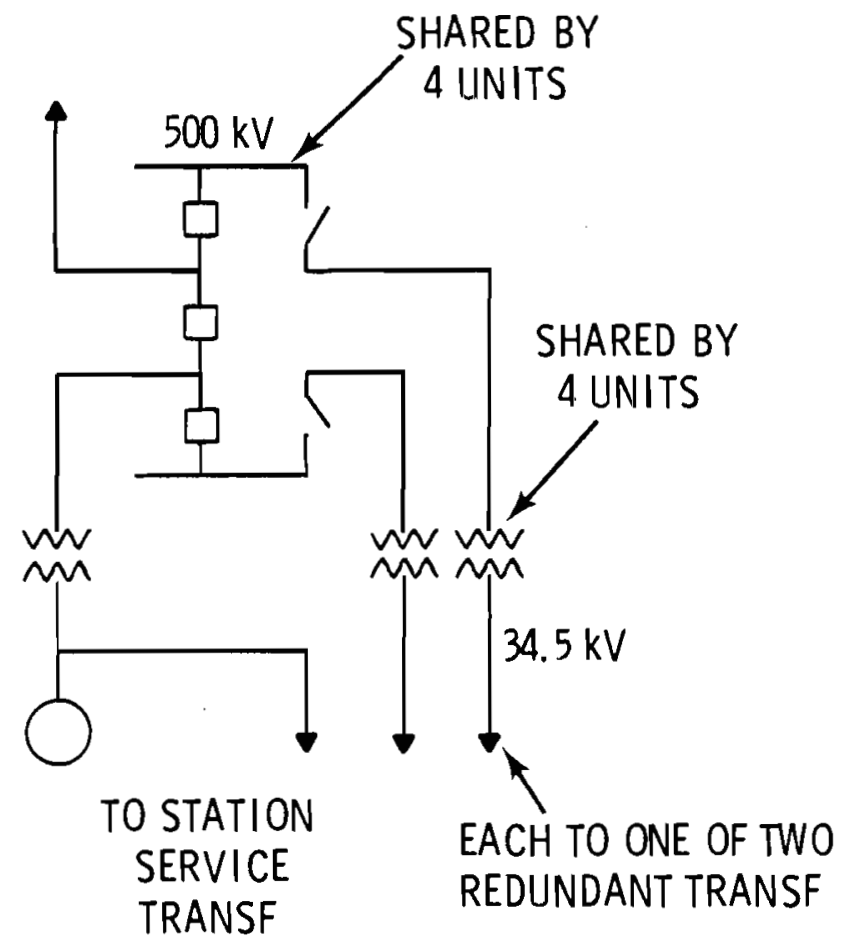

FIGURE B.5. North Anna - 4 Units

TO NETWORK

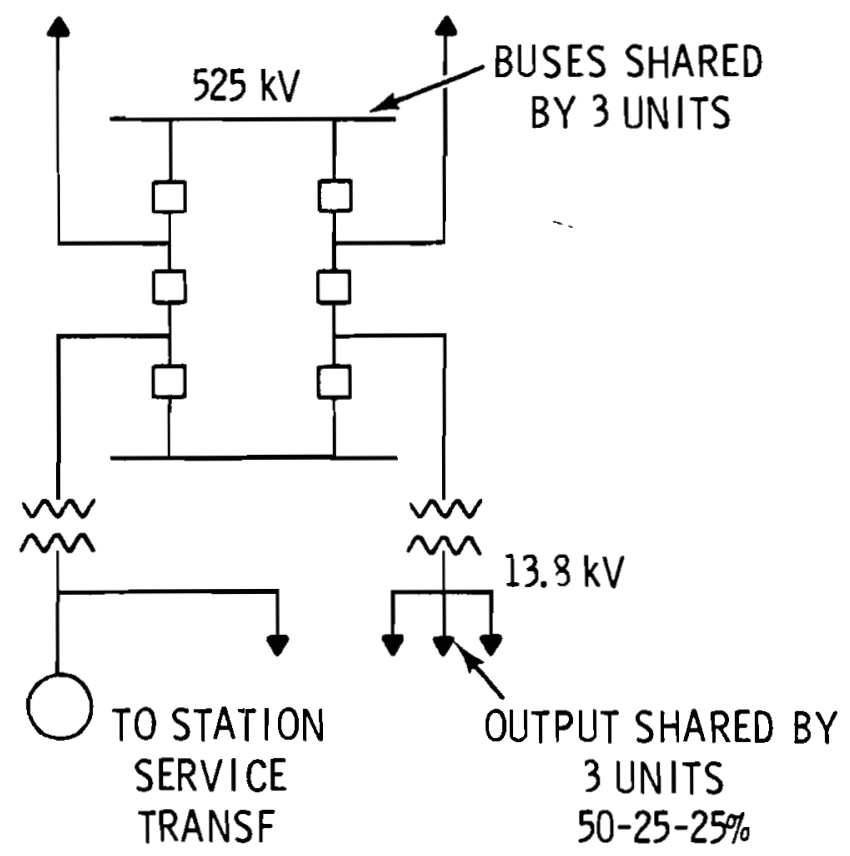

FIGURE B.6. Palo Verde - 3 Units 


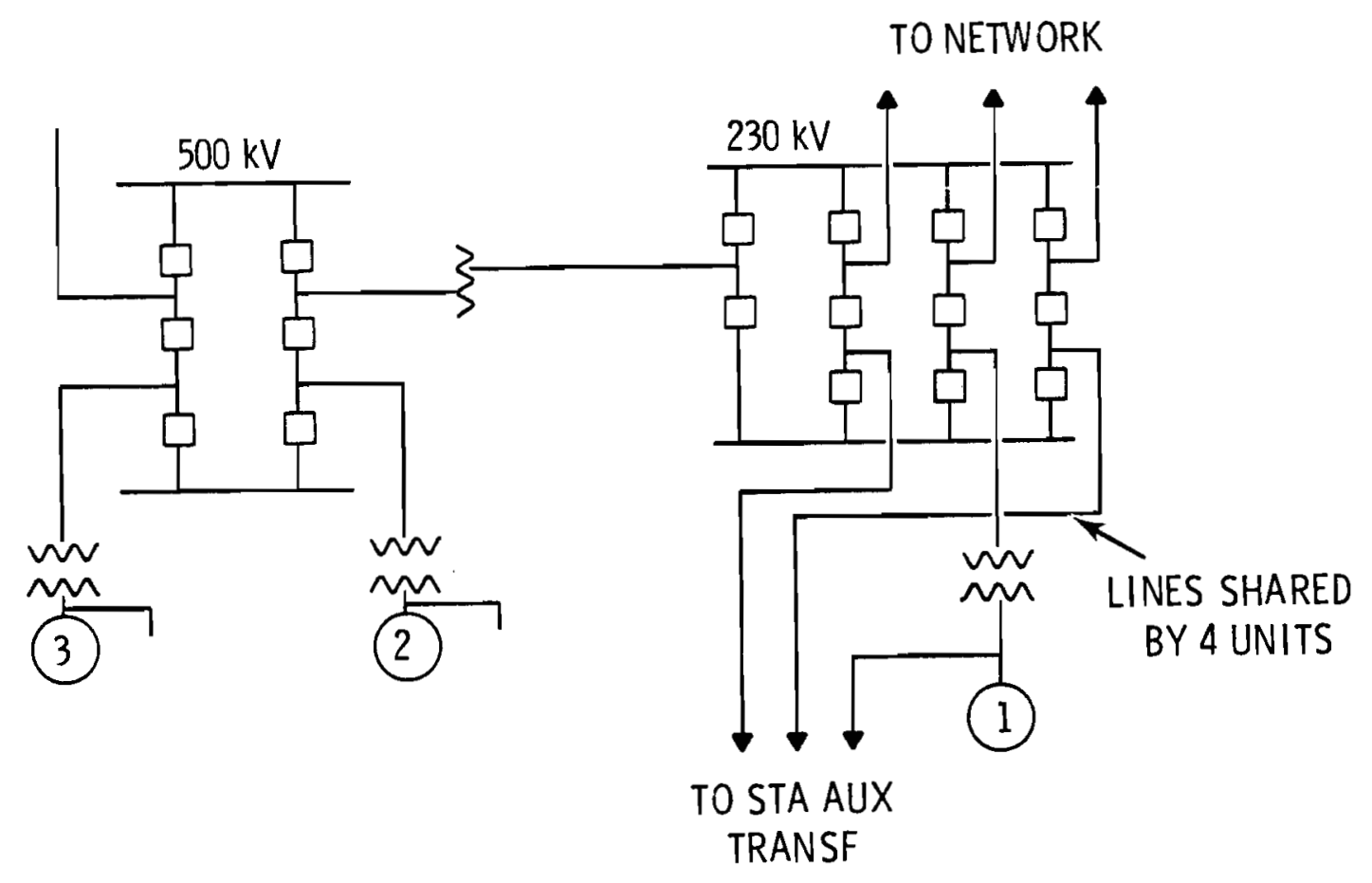

FIGURE B.7. Alan Barton

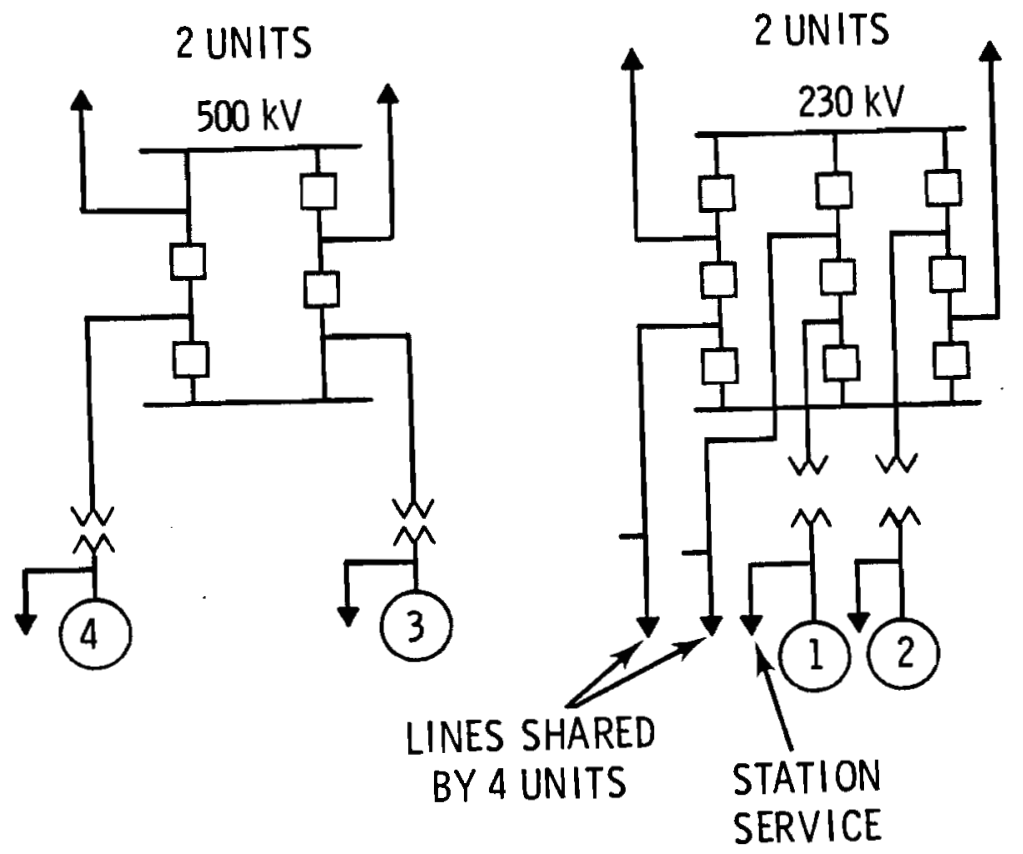

FIGURE B.8. Shearon Harris 


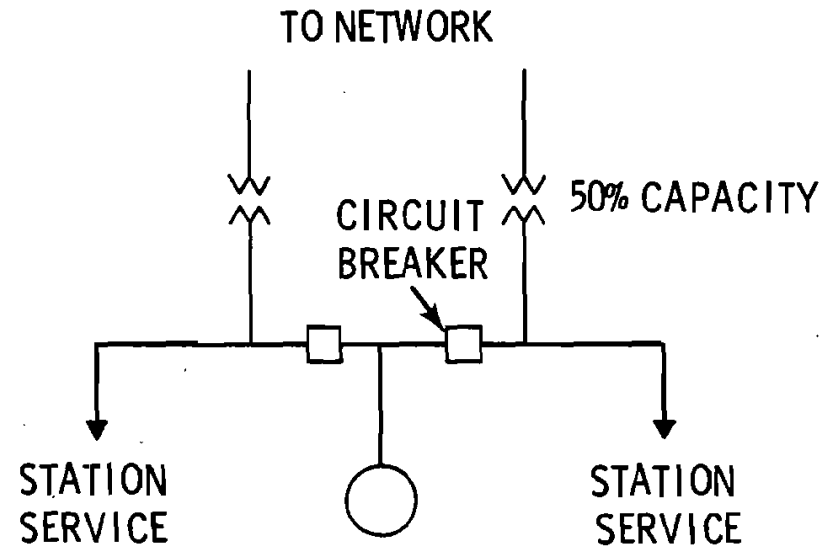

FIGURE B.9. McGuire (a 2-unit plant)

TABLE B.1. Number of Generating Units Sharing Station Service Circuits and Equipment

\begin{tabular}{|c|c|c|c|c|c|c|c|c|}
\hline Current Designs & Units & $\begin{array}{c}\text { Entry to } \\
\text { Network } \\
\text { through } \\
\text { Conmon } \\
\text { High Vol tage } \\
\text { Switchyard } \\
\end{array}$ & $\begin{array}{c}\text { Entry to } \\
\text { Network } \\
\text { through } \\
\text { Comon } \\
\text { Low Voltage } \\
\text { Switchyard } \\
\end{array}$ & $\begin{array}{c}\text { One } \\
\text { Circuit } \\
\text { from } \\
\text { Tie Point } \\
\end{array}$ & $\begin{array}{c}\text { Two } \\
\text { Circuits } \\
\text { from } \\
\text { Tie Point } \\
\end{array}$ & 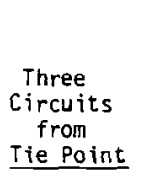 & $\begin{array}{r}\text { Two } \\
\text { Inter- } \\
\text { mediate } \\
\text { Trans- } \\
\text { formers } \\
\end{array}$ & $\begin{array}{l}\text { Station } \\
\text { Service } \\
\text { Trans- } \\
\text { formers } \\
\end{array}$ \\
\hline Hanford & 5 & 4 & 5 & 1 & 5 on loop & -- & -- & 1 \\
\hline Hartsville & 4 & 2 & 2 & -- & 2 & -- & -- & 1 \\
\hline Alvin Vogtle & 4 & -- & 4 & -- & 4 & -- & -- & 1 \\
\hline North Anna & 4 & 4 & -- & -- & 4 & -- & 4 & 1 \\
\hline Palo Verde & 3 & 3 & -- & -- & - & 3 & -- & 3 \\
\hline Alan Barton & 4 & -- & 4 & -- & 4 & -- & -- & 1 \\
\hline Shearon Harris & 4 & -- & 4 & -- & 4 & -. & -- & 1 \\
\hline
\end{tabular}




\section{APPENDIX C}

The load-flow diagrams of Appendix $C$ conta in the results of studies of methods of reinforcing the BPA $230 \mathrm{kV}$ system in the vicinity of the Hanford reservation in order to provide sufficient capacity for the station service loads of 20 nuclear generating units. 


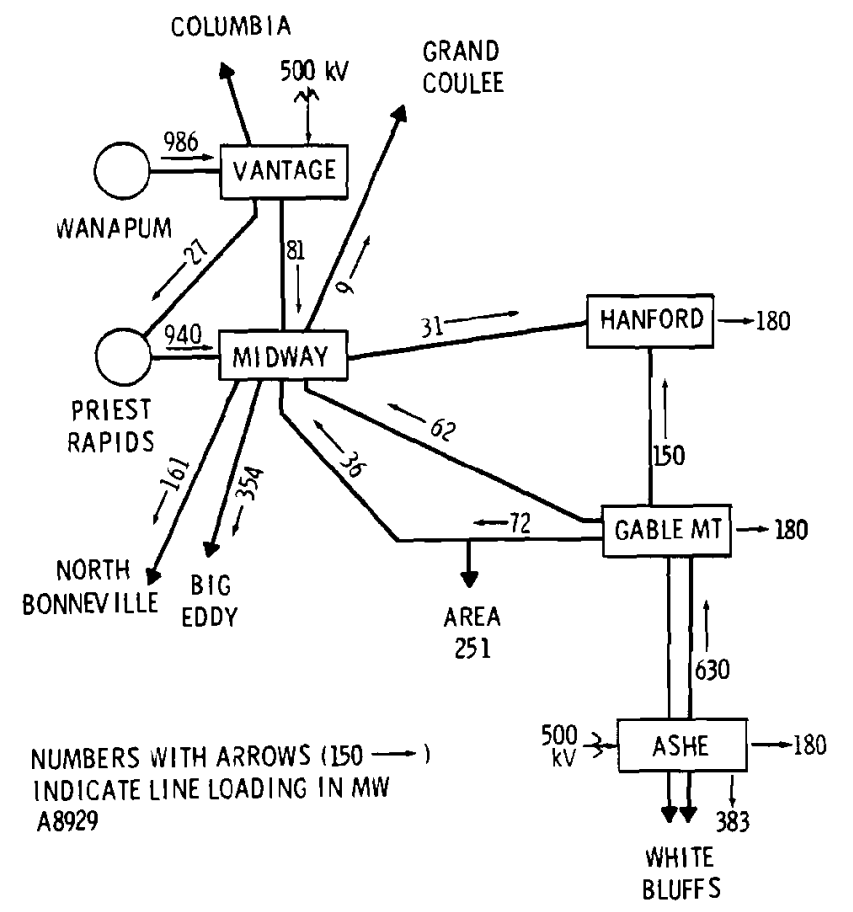

FIGURE C.1. Hanford Area $230 \mathrm{kV}$ System with $180 \mathrm{MW}$ Load at Hanford, Gable Mt., and Ashe. 115-kV system sectionalized between Midway and Franklin.

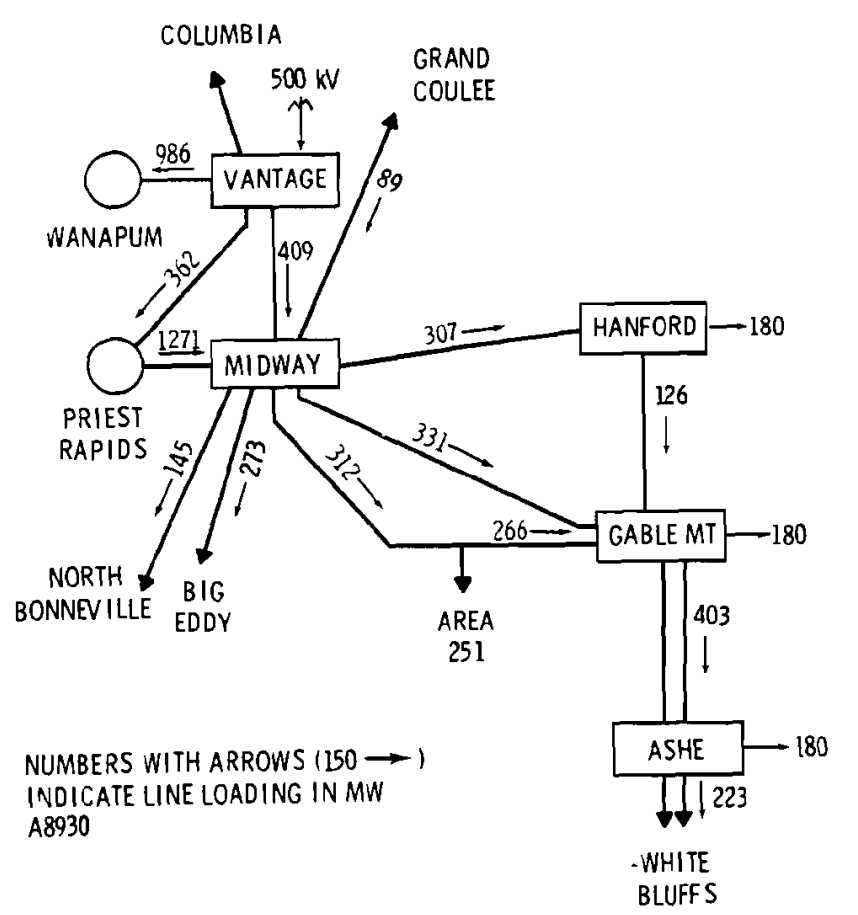

FIGURE C.2. Hanford Area $230 \mathrm{kV}$ System with $180 \mathrm{MW}$ Load at Hanford, Gable Mt., and Ashe. 115-kV system sectionalized. 


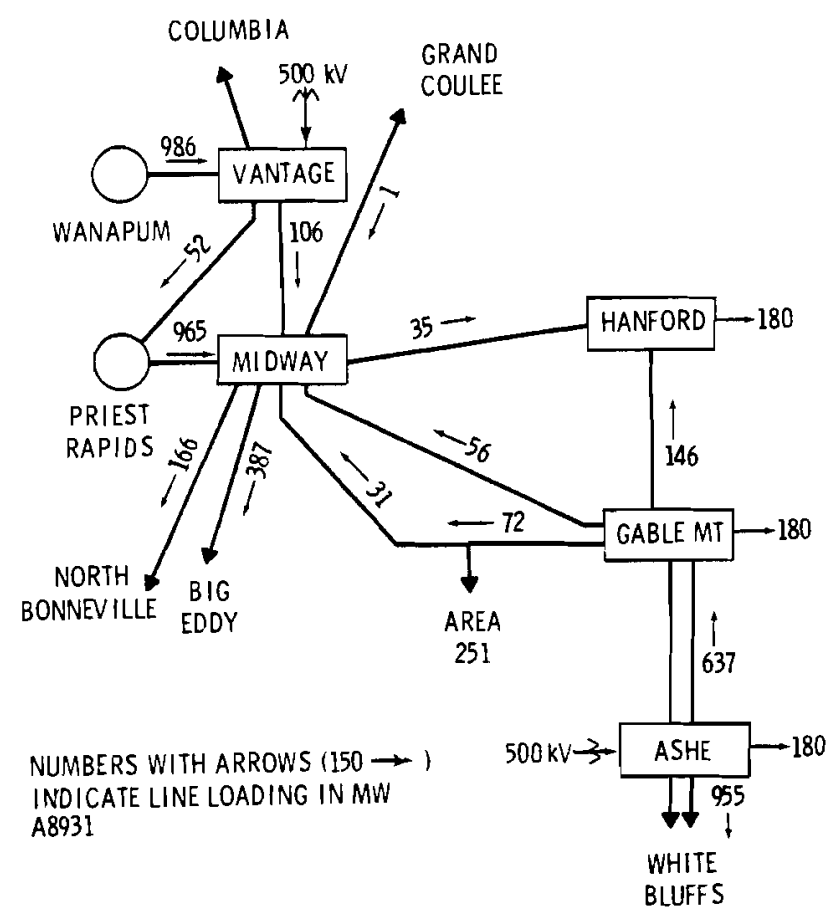

FIGURE C.3. Hanford Area $230 \mathrm{kV}$ System with 180 MW Load at Hanford, Gable Mt., and Ashe. McNary-John Day $500 \mathrm{kV}$ Connection.

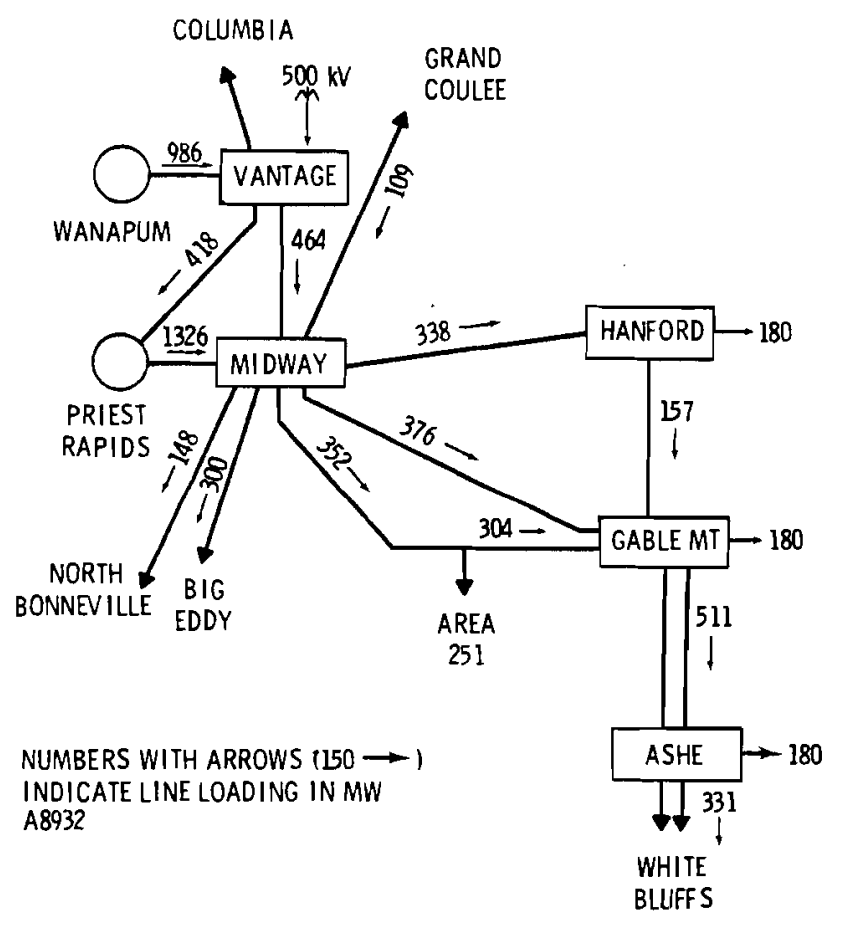

FIGURE C.4. Hanford Area $230 \mathrm{kV}$ System with 180 MW Load at Hanford, Gable Mt., and Ashe. 


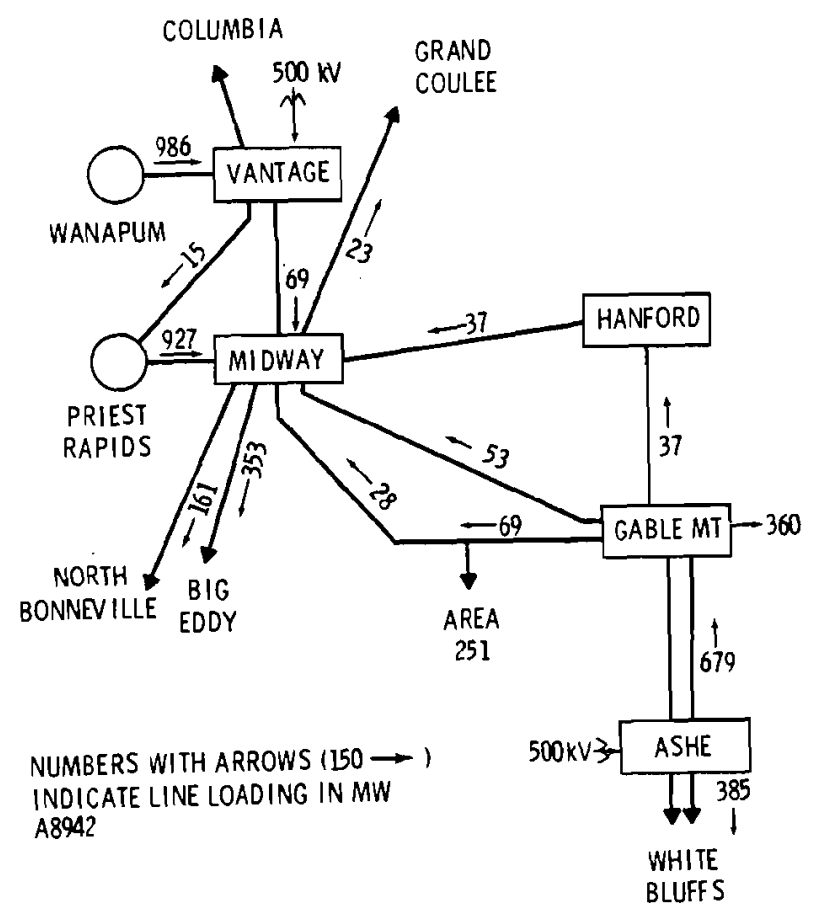

FIGURE C.5. Hanford Area $230 \mathrm{kV}$ System with 360 MW Load at Gable Mt.

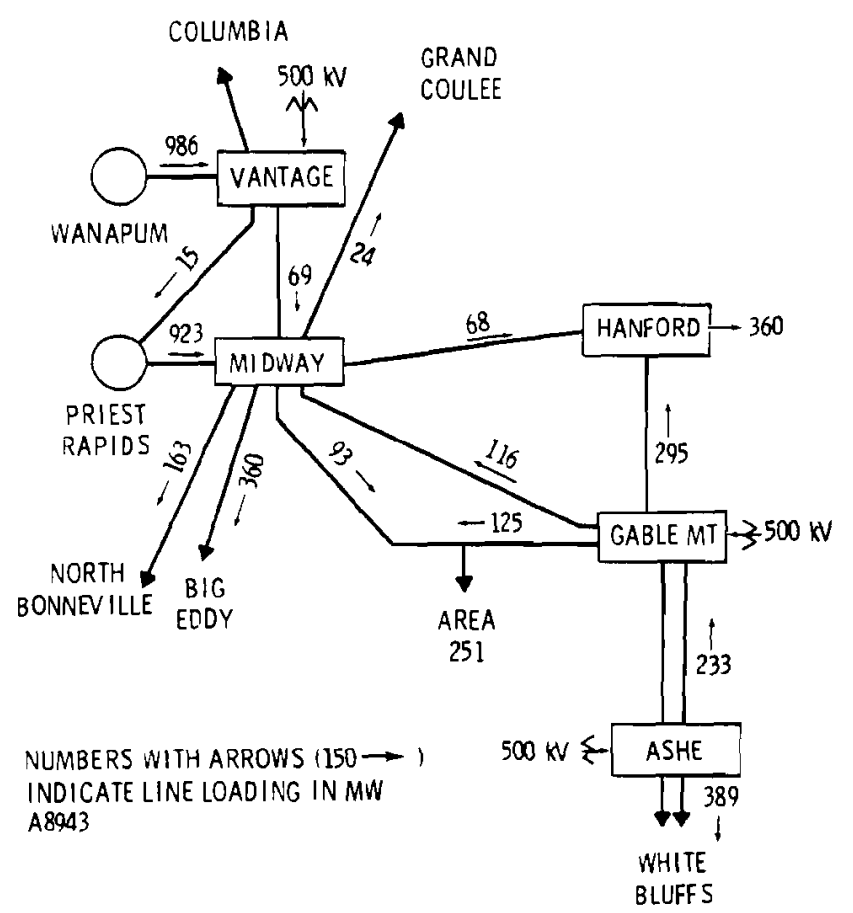

FIGURE C.6. Hanford Area $230 \mathrm{kV}$ System with 360 MW Load at Hanford. Scootenay reinforced, 115-kV system sectionalized. 


\section{APPENDIX D}

\section{Typical Configurations of Groups of Generating Plants}

Assuming the base conditions stated in the "HNEC Base Conditions" section, the general layout of $\mathrm{plants}$ and lines in the southern (Ashe), central (Gable Mountain), and northern (Hanford) groups of units would be as illustrated in Figures D.1 through D.3. These figures show only the reactorgenerator plant buildings, lines and switching stations, and exclude cooling towers and other plant ancillary structures and facilities. The $230 \mathrm{kV}$ line taps and extensions would be added only if the $230 \mathrm{kV}$ system were selected for station service.

Figures 0.4 through 0.6 show, to a larger scale than Figures 0.1 through D.3, the orientation and spacing of the generators, transformer bays, and the switchyard for the multiple-unit groups of: (1) WPPSS plants near the Ashe switching station, (2) Alan Barton four-unit stations used as an example for one group near the Gable Mountain switching station and one near the Hanford switching station, and (3) Palo Verde three-unit stations used as an example for one group near the Hanford switching station. The orientation and spacing illustrate the relative problem of getting station service circuits into the transformer bays, the amount of underground cable that may be required, and the line spacing. Examination of these different designs reveals the measures that must be taken to provide station service. 


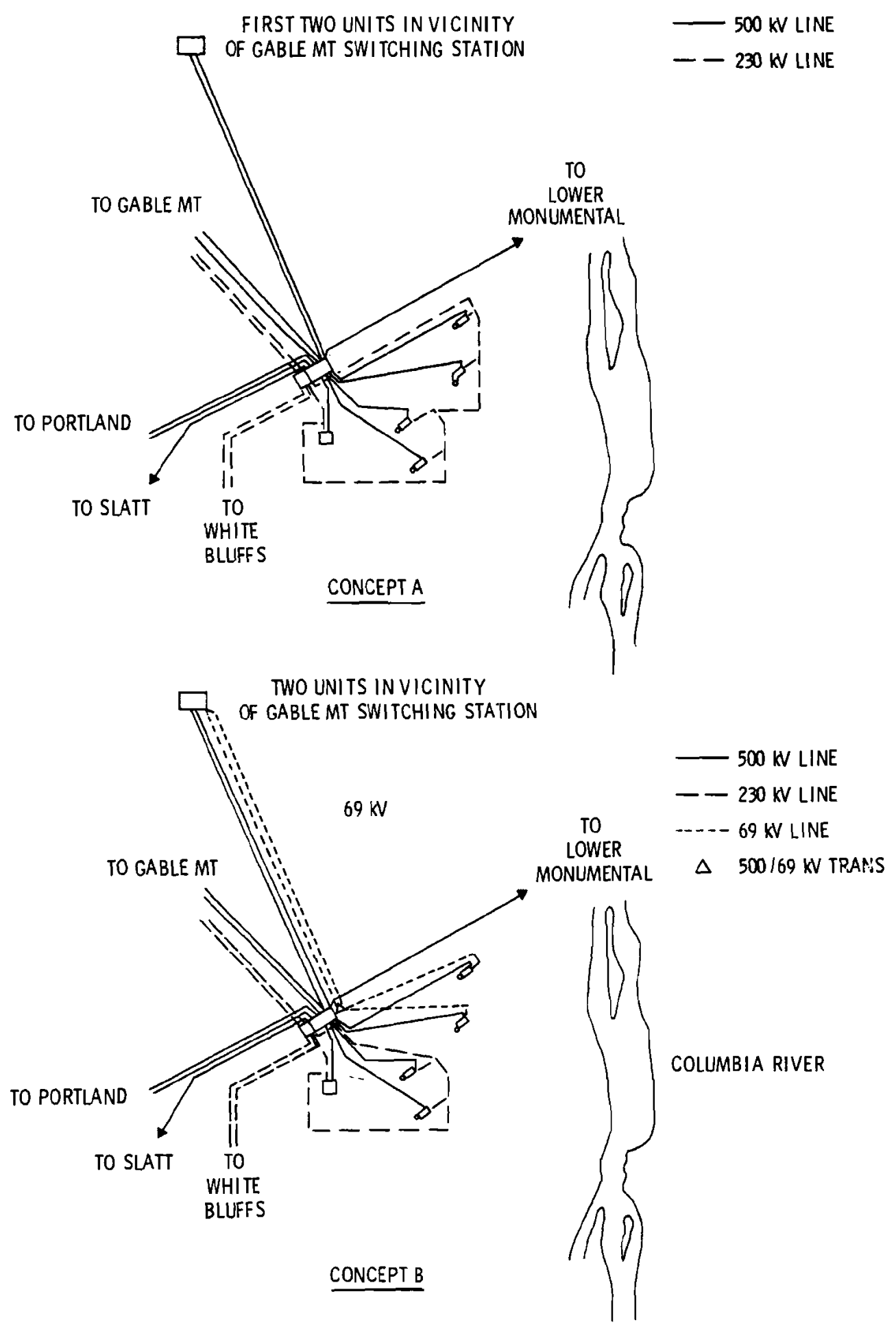

FIGURE D.1. Map of Facilities in Vicinity of Ashe Switching Station 

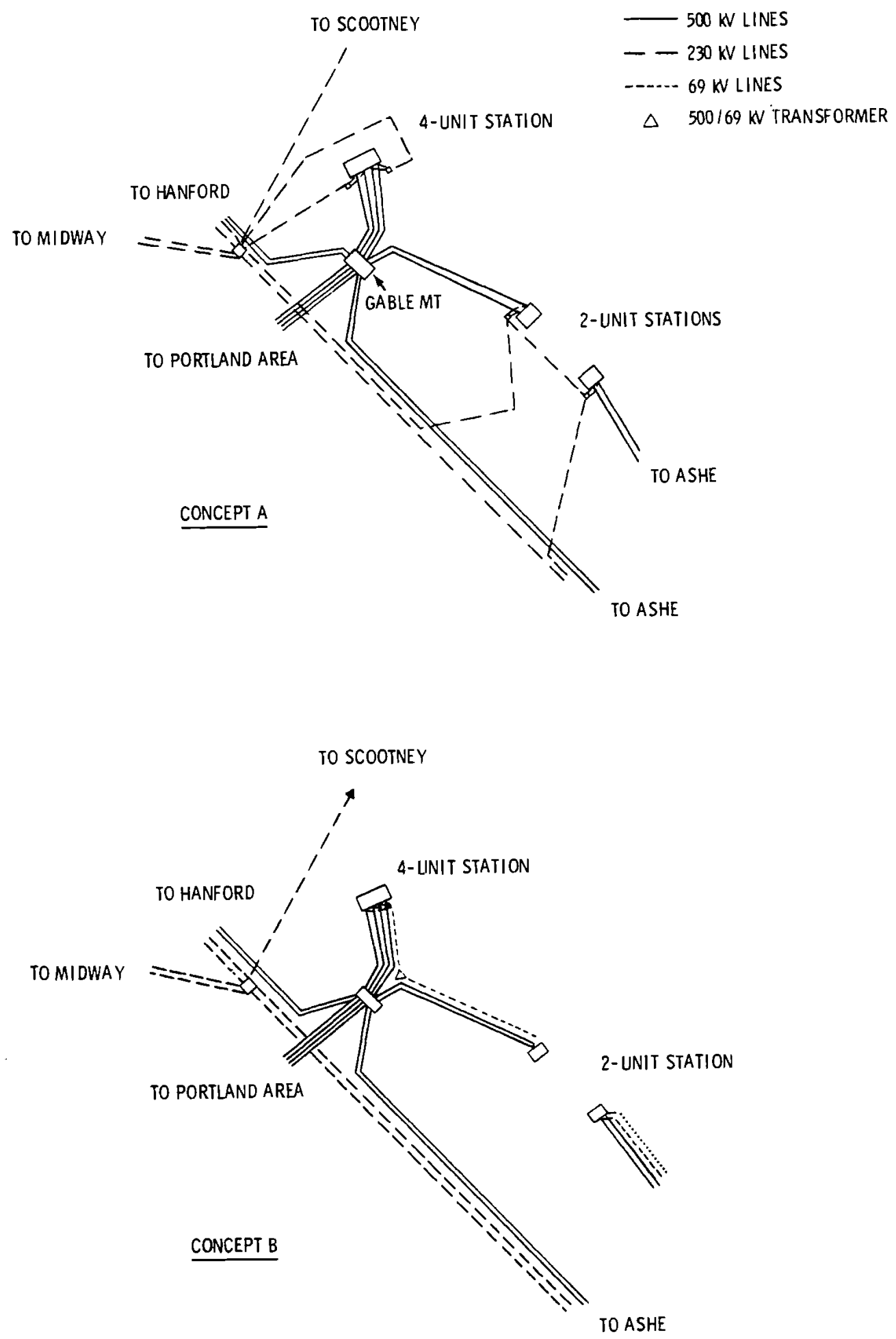

FIGURE D.2. Map of Facilities in Vicinity of Gable Mountain Switching Station 


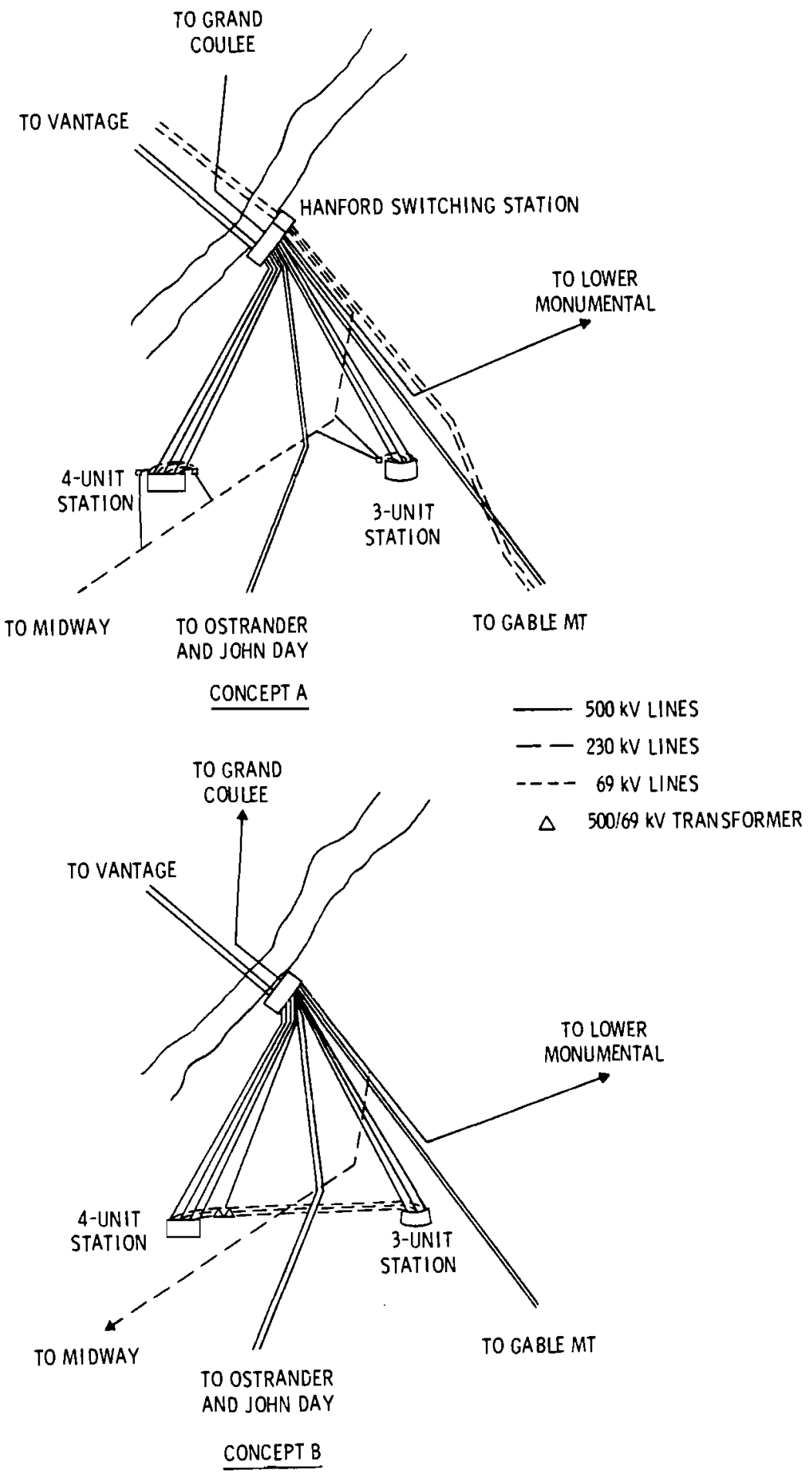

FIGURE 0.3. Map of Facilities in Vicinity of Hanford Switching Station 


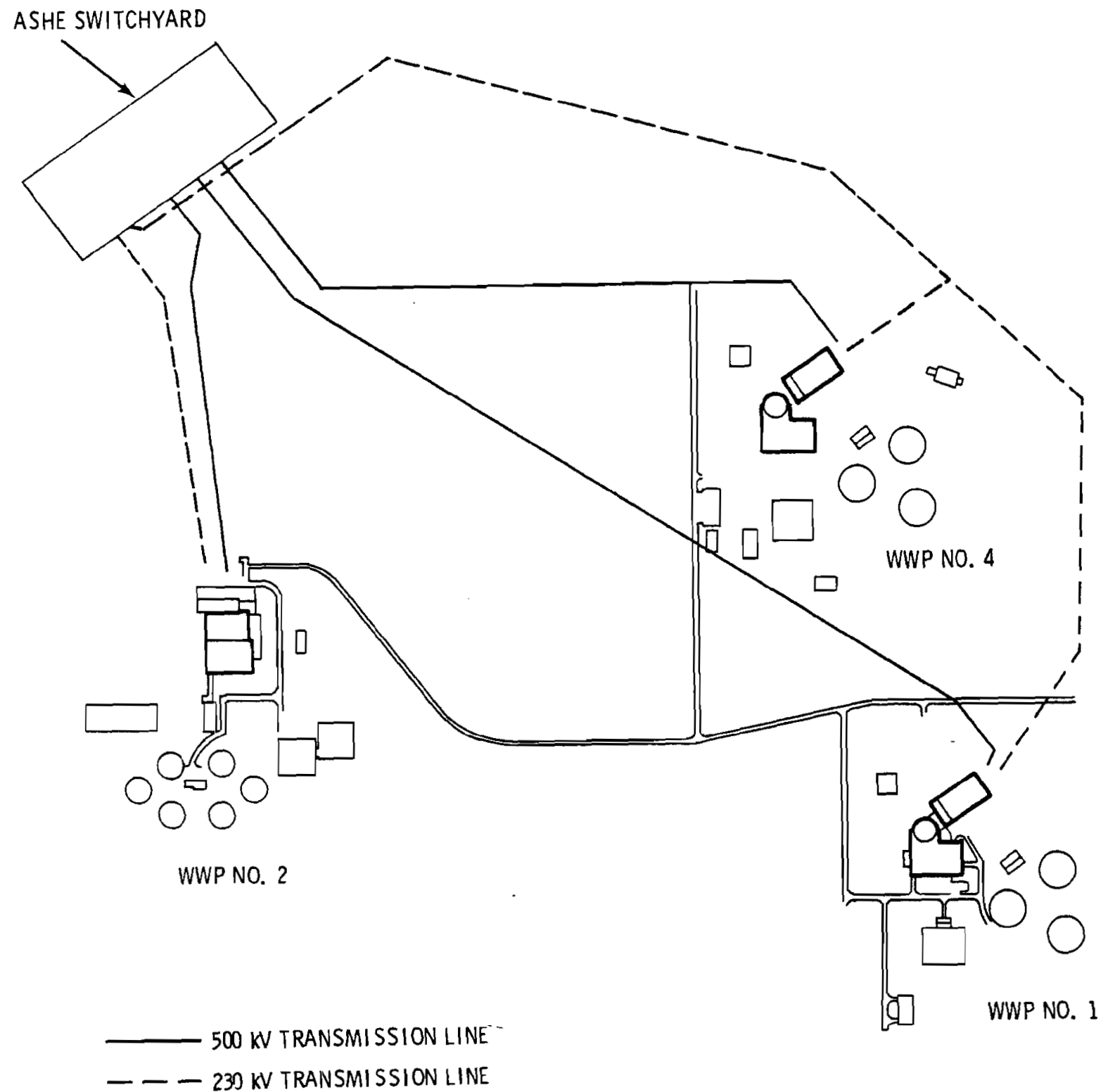

FIGURE D.4. Orientation of Principal Structures Planned for Hanford Plants 


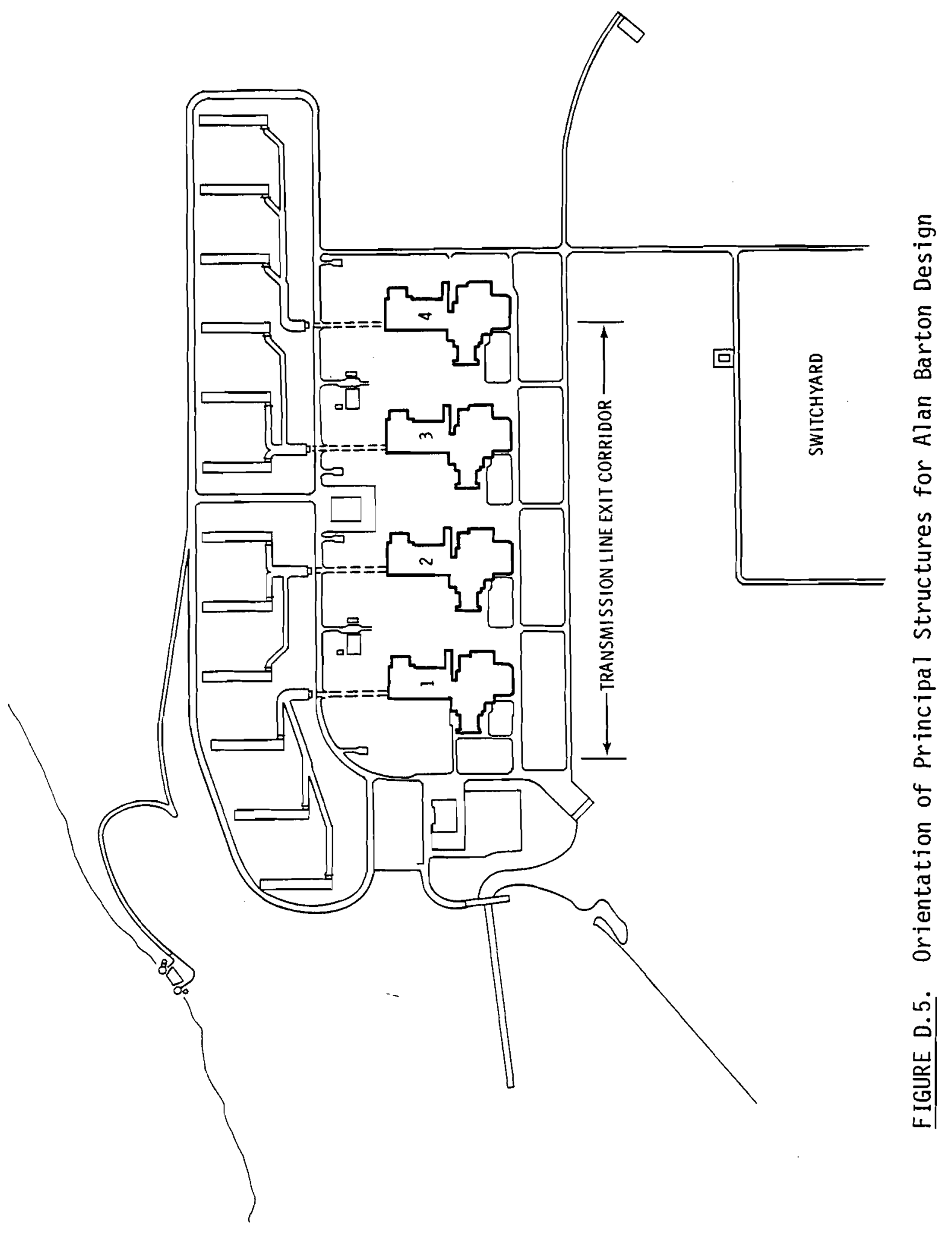




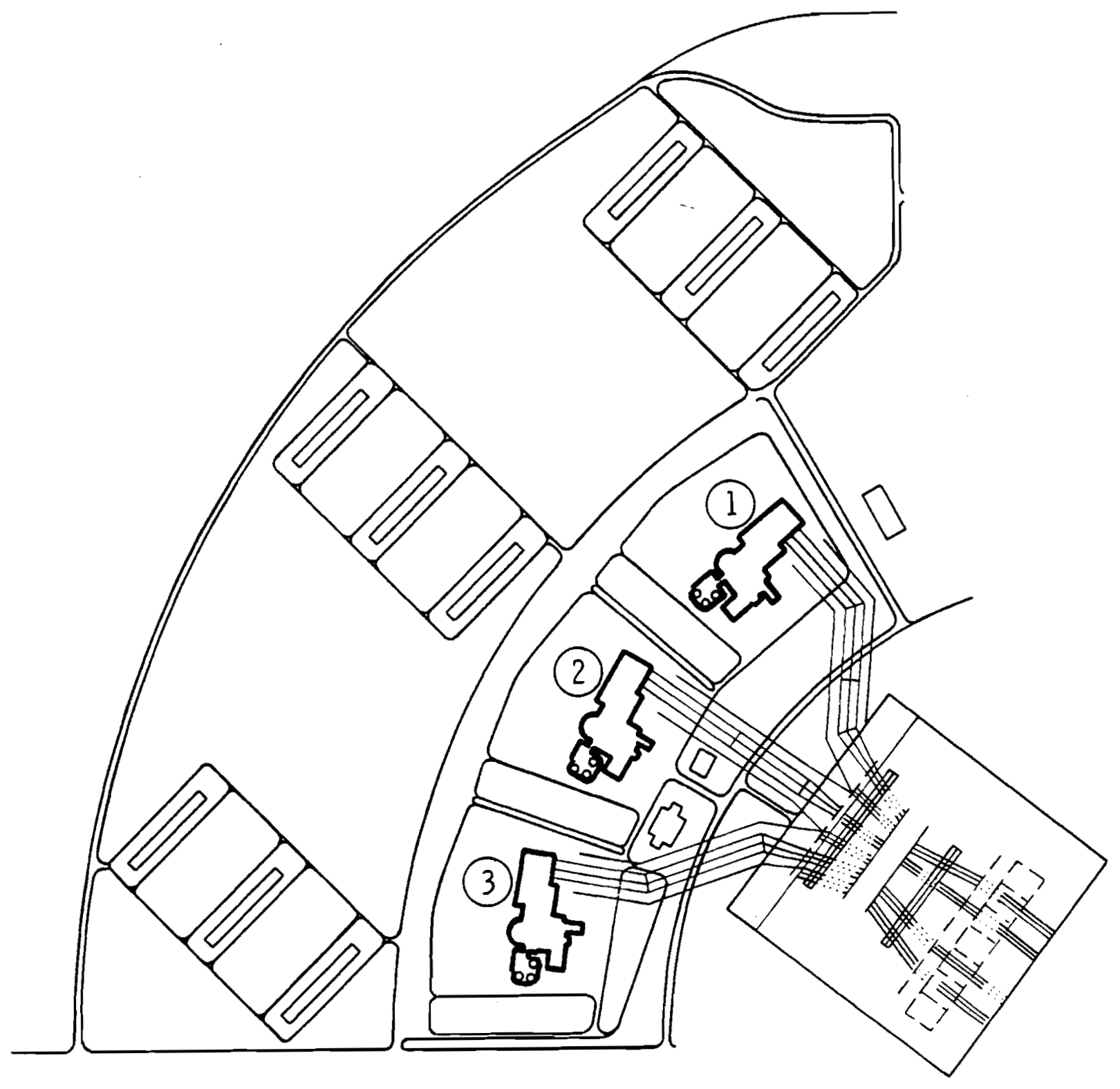

FIGURE D.6. Orientation of Principal Structures for the Palo Verde Plant 


\section{DISTRIBUTION}

No. of

Copies

OFFSITE
No. of

Copies
A. A. Churm

ERDA Chicago Patent Group

9800 South Cass Ave.

Argonne, IL 60439

Lyman J. Harris

Northwest Area Power Manager

Aluminum Company of America

P.0. Box 120

Vancouver, WA 98660

Robert W. Blodgett

Manager, Benton County

Public Utility District

P.0. Box 6273

Kennewick, WA 99336

C. Ray Foleen

Deputy Administrator

Bonneville Power

Administration

P.0. Box 3621

Portland, OR 97208

9 Ralph Gens

Bonneville Power Administration

P.0. Box 3621

Portland, OR 97208

Gordon Culp

Culp, Dwyer, Guterson

\& Grader

1300 Hoge Building

Seattle, WA 98704

Laura Henning

Electric Power Research Institute

P.0. Box 104.12

Palo A7to, CA 94304
10 Theodore Beresovski

Chief, Advanced Concepts

Energy Research and

Development Administration

Mai] Stop F-309

Washington, DC 20545

27 ERDA Technical Information Center

Nuclear Regulatory Commission

Washington, DC 20555

Howard C. Elmore

Chairman

Pacific Northwest Utilities Conference Committee

P.0. Box 1231

Wenatchee, WA 98801

David J. Lewis

Consultant, Pacific Northwest

Utilities Conference Committee

on Engineering and Planning

2730 Northwest 77 th Place

Portland, OR 97213

A. J. Porter, Vice President Portland General Electric Co. 621 Southwest A7der St.

Portland, OR 97205

John W. Ell is

Puget Sound Power \& Light Company

Puget Power Building

P.0. Box 535

Bellevue, WA 98004

Jack Criswe11, General Manager

Springfield Utility Board

250 North "A" St.

Box 300

Springfield, OR 97477 
No. of

Copies

R. KToman

National Academy of Public Administration

1225 Conn Ave. N.W.

Washington, DC 20036

2 Keith Sherman

Washington State Energy Office

1000 South Cherry

Olympia, WA 98504

15 Roger Polzin

Energy Facility Site

Evaluation Council

820 E. Fifth Ave.

OTympia, WA 98504

2 W. Kelly Woods

Oregon Department of Energy

528 Cottage St. N.E.

Salem, OR 97310
No. of

Copies

\section{Battelle-Northwest}

R. G. Clark

W. J. Dowis

E. A. Eschbach

S. J. Farmer

J. W. Finnigan

20 H. Harty

A. J. Haverfield

W. R. McSpadden

R. L. Richardson

L. C. Schmid

J. R. Young

5 Technical Information

3 Technical Publications

\section{ONSITE}

Washington Public Power

Supply System

D. Thonn

7 ERDA Richland Operations Office

0. J. Elgert

P. W. Gottschalk

R. H. Lindsey/G. L. Liffick

F. R. Standerfer

M. W. Tiernan

Research and Development

Programs Division

2 W. A. Burns 